\title{
Emmanuel Kamdem
}

\section{L'Analyse des Organisations en Afrique: Un Champ de Recherche Emergent}

\section{Résumé}

L'organisation, concept fondamental en sciences sociales et en sciences de gestion, a fait l'objet d'une abondante littérature qui a permis à l'analyse des organisations de devenir progressivement un champ de recherche dominant. Ce champ de recherche s'est d'abord développé en Amérique du Nord, principalement aux Etats-Unis, où ont été réalisés les premiers travaux systématiques sur l'organisation; travaux essentiellement consacrés aux problèmes de fonctionnement des unités de production économique. A la faveur de l'exportation dans d'autres régions du monde du modèle américain de gestion et des paradigmes qui le sous-tendent, après la deuxième guerre mondiale, l'analyse des organisations a connu des développements importants en Europe, en Amérique du Sud et en Asie. L'Afrique, longtemps restée en marge de cette évolution, commence à son tour à connaître un regain d'intérêt pour l'organisation en tant qu'objet d'étude; et ce à partir des années quatre-vingt. C'est à cette situation nouvelle que s'intéresse l'auteur de ce texte en proposant une réflexion articulée autour de deux axes majeurs. D'une part, effectuer un survol de la littérature sur les organisations en tentant de dégager les principales perspectives d'analyse et, d'autre part, porter un regard sur la production africaine actuelle afin d'élucider les conditions de son émergence et d'évaluer les possibilités de son développement. L'utilité et la pertinence de la présente réflexion se justifient par la nécessité de construire un discours à la fois cohérent et réaliste sur l'organisation en Afrique, tout en adoptant une posture à l'égard des discours antérieurs et actuels sur l'organisation ailleurs dans le monde, notamment en Occident.

\section{Introduction}

Pourquoi, à l'heure de la mondialisation envahissante, s'intéresser encore à l'analyse des organisations en Afrique? Beaucoup se posent sûrement cette question et s'interrogent sur l'utilité et la pertinence d'une telle démarche, eu égard à l'abondance et à la richesse de la réflexion sur les organisations ailleurs dans le monde et principalement en Occident. Or c'est justement cette abondance et cette richesse qui contrastent avec l'insuffisance et la faiblesse de la production africaine sur la question. Est-ce parce que les organisations 
africaines n'ont suscité et ne suscitent qu'un faible intérêt chez les spécialistes des sciences sociales d'Afrique et d'ailleurs? Ou que la production mondiale actuelle sur les organisations est suffisamment enrichissante et avancée pour ne pas justifier de nouveaux errements sur des terrains peu connus? Il y a quelques années, j'ai reçu comme un choc (et un défi) cette déclaration cinglante d'un dirigeant politique africain à qui je m'efforçais vainement d'expliquer ma profession d'enseignant chercheur en sociologie des organisations: Qu'est-ce que vous cherchez encore en Afrique? Cherchez d'abord à bien utiliser ce que l'Occident a déjà produit au lieu de vous engager à réinventer ce qui existe déjà $\grave{1}^{1}$ Cette position à elle seule est suffisamment significative (et discutable) pour justifier mon propos actuel qui s'articule autour de deux axes majeurs. D'abord, une tentative d'élucidation du concept d'organisation et une présentation des principales perspectives qui se dégagent de la production sur 1'analyse des organisations. Et ensuite, l'évaluation de la production africaine actuelle sur la question ainsi que des difficultés et des opportunités de son développement.

\section{L'Organisation...}

Avant d'aller au cœur du sujet sur l'analyse des organisations, il est sans doute utile de rappeler assez brièvement ce qu'est une organisation, concept central en sociologie et en management. De manière très générale, il s'agit d'un groupement de personnes poursuivant des objectifs plus ou moins déclarés et partagés, et qui par ailleurs se donnent les moyens pour la réalisation de ces objectifs. Une telle définition s'enracine dans une vision globale de la société en termes d'ensembles structurés et fonctionnels. Ce constat du sociologue A. Etzioni (1971, p. 11) traduit bien cette manière de voir 1'organisation: Nous sommes nés dans des organisations, avons été éduqués par des organisations, et la plupart d'entre nous consacrent une grande part de leur existence $\grave{a}$ travailler pour des organisations. De ce fait et dans la perspective définie par l'auteur, l'organisation présente un certain nombre de caractéristiques principales:

- l'institutionnalisation de la division du travail, du pouvoir et des responsabilités de communications;

- la présence d'un ou de plusieurs centres de décision qui exercent une fonction de contrôle et d'orientation de l'activité des membres de l'organisation;

- la mobilité de ces derniers qui s'opère suivant les objectifs organisationnels et les potentialités individuelles des membres.

Ces caractéristiques conduisent à voir l'organisation essentiellement comme un corps social plus ou moins structuré, vivant et dynamique, dont la décomposition et la recomposition se produisent au quotidien. Cette approche constructiviste est très importante dans la mesure où elle permet de ne plus 
aborder l'organisation simplement sous l'angle de l'adaptation nécessaire aux contraintes extérieures produites par l'environnement, mais beaucoup plus comme un construit par des acteurs intégrant les contraintes comme éléments des stratégies. ( $\mathrm{Ph}$. Bernoux, 1985, p. 116). A l'intérieur de cet ensemble construit, il s'opère des transformations et des changements. En quelques mots, ça bouge au quotidien. Cette transformation interne permanente se réalise aussi bien au niveau des structures, des procédures qu'à celui des individus. L'analyse d'une organisation est donc la démarche permettant d'aller au cœur de celle-ci pour tenter d'identifier et d'élucider les dynamiques sociales qui s'y déroulent, puis de les examiner en rapport avec les stratégies d'acteurs et le contexte général (l'environnement) dans lequel évolue cette organisation.

\section{... Et son Analyse}

L'analyse des organisations est une démarche ancienne dont les premières tentatives apparaissent au début du siècle dernier et principalement en Occident, avec le développement accéléré des activités et des structures de production économique. Ce phénomène a amené les spécialistes de tous bords (économistes, ingénieurs, psychologues, sociologues, gestionnaires et spécialistes des sciences de gestion) à se pencher davantage sur le fonctionnement de ce type de structures. Les uns pour rechercher les voies et moyens susceptibles de conduire à une plus grande efficience productive de ces dernières, les autres pour relever les conséquences sur l'individu et le corps social de l'efficience productive recherchée. Depuis lors, l'organisation est devenue un objet d'étude prisé et un lieu de rencontre de plusieurs disciplines (B. Lussato, 1977; J.-F. Chanlat, 1989, 1991, 1998; J.-F. Chanlat et F. Séguin, 1983; F. Séguin et J.-F. Chanlat, 1988; G. Morgan, 1989; O. Aktouf, 1990a). Sans chercher à faire une présentation complète des différents champs disciplinaires d'analyse de l'organisation et au regard de l'évolution des courants d'étude observés, on peut esquisser un rapide survol des différentes perspectives suivant lesquelles l'organisation a été étudiée. Pour bien marquer l'évolution et le changement des perspectives dans le temps, on tentera chaque fois d'élucider le contexte et les conditions d'émergence des différentes perspectives. Ce rappel est nécessaire et essentiel pour comprendre les circonstances et les raisons du développement tardif en Afrique des recherches sur l'analyse des organisations.

\section{La perspective rationaliste et fonctionnaliste}

C'est l'approche pionnière observée dans l'analyse des organisations. C'est aussi celle qui a suscité le plus grand nombre d'études critiques. Cette perspective peut se résumer en quelques termes de référence: recherche d'une plus grande rationalisation, analyse méthodique du travail, renforcement de l'efficacité productive, quête de la rentabilité financière, etc. On se situe entre 
la deuxième moitié du dix-neuvième et le début du vingtième siècle, période charnière entre celle de la machine-outil et de la production artisanale en petite série d'une part, et celle de l'automation et de la production en grande série d'autre part. Ces transformations se traduisent par de nouvelles exigences dans le domaine de l'organisation et de la rationalisation du travail. D'où l'urgence d'élaborer des méthodes de travail susceptibles de renforcer la capacité productive des personnes et des organisations. Les courants rattachés à cette première perspective s'intéressent à trois sous-champs d'étude: celui du travail ouvrier en atelier, celui du travail administratif de direction et celui de l'organisation administrative bureaucratique.

\section{L'analyse technique du travail d'atelier}

Ce courant initial insiste beaucoup sur l'organisation à la fois technique et rentable du travail dans les ateliers de production. Les travaux fondateurs remontent à F. W. Taylor (1856-1915) dont l'intérêt pour l'entreprise et son organisation apparaît à un moment crucial du développement industriel et économique de l'Occident. F. W. Taylor, américain, a connu une carrière professionnelle très précoce. Quelques ennuis de santé l'ont conduit à arrêter ses études très tôt et à s'imprégner des réalités du monde industriel dans lequel il va connaître une évolution professionnelle rapide (apprenti, ouvrier mécanicien, contremaître, ingénieur, conseil en organisation). Ce cheminement professionnel lui fait prendre conscience très rapidement des multiples problèmes d'organisation et de fonctionnement des ateliers de production (description des tâches, allocation des temps, détermination des normes de rendement, sélection et motivation du personnel ouvrier). A ses yeux, la solution à ces différents problèmes passe par une analyse méticuleuse et approfondie du travail et la prescription des méthodes de production susceptibles de permettre une amélioration quantitative des résultats. Toute cette démarche est explicitée dans son ouvrage célèbre sur la direction scientifique des entreprises, publié en 1911. On peut à juste titre considérer ce dernier comme l'ouvrage fondateur de l'analyse du travail, en ce sens que l'auteur se met au cœur de l'organisation (l'usine industrielle) pour tenter d'identifier les problèmes liés à son fonctionnement et proposer des solutions pour les résoudre. En schématisant, on peut dire que la démonstration de $\mathrm{F}$. W. Taylor repose sur quatre principes directeurs ${ }^{2}$ : la consécration du rôle central voire exclusif des dirigeants dans la définition des procédures d'exécution du travail, la sélection méthodique et rigoureuse du personnel ouvrier et leur formation au métier, la collaboration indispensable entre le personnel dirigeant et le personnel ouvrier, la détermination et le partage des responsabilités entre ces deux catégories de personnel pour permettre à chacun de pouvoir faire ce pour lequel il est supposé être plus apte.

Avec le recul du temps, on se rend bien compte aujourd'hui que la démarche inaugurée par F. W. Taylor a été très déterminante pour l'évolution des tech- 
niques d'organisation du travail et de l'entreprise. Les principes d'organisation qu'il a formulés ont connu des applications diverses et suscité des critiques variées (H. Braverman, 1976). Quelque soient les applications et les critiques faites ici et là partout dans le monde, il faut reconnaitre à Taylor le mérite d'avoir posé les jalons d'une vision nouvelle de l'organisation et du travail; vision qui demeure encore d'actualité après près d'un siècle. On ne peut cependant pas oublier d'insister sur le fait qu'une telle vision productiviste et rentabiliste ne tient pas suffisamment compte de la relativité du contexte social et de la versatilité de l'être humain qui devient en quelque sorte prisonnier de la mécanique infernale de la production.

\section{$L$ 'analyse administrative du travail du dirigeant}

Cette approche est développée par H. Fayol (1841-1925), ingénieur français dont le cheminement professionnel présente quelques similitudes avec celui de F. W. Taylor (formation d'ingénieur, directeur d'usine dans le secteur minier, directeur d'entreprise minière en difficulté dont il entreprend et réussit la restructuration, conseil en organisation). Le contexte économique en France à l'époque est presque identique à celui des Etats-Unis où réside $\mathrm{F}$. W. Taylor: croissance économique, développement des techniques industrielles, nécessité d'une plus grande rationalisation des systèmes de production. De son enrichissante expérience comme dirigeant ayant piloté avec succès un projet de restructuration et de redressement d'entreprise $^{3}$, il tire un certain nombre d'enseignements essentiels sur la portée stratégique de certaines activités de direction auxquelles les dirigeants ne semblent pas accorder l'intérêt qu'elles méritent. Il regroupe ces activités (opérations) ${ }^{4}$ dans le cadre d'une fonction dont il souligne l'importance vitale pour l'entreprise: la fonction administrative. Il trouve que celle-ci est restée longtemps négligée par beaucoup de dirigeants, alors même qu'elle consacre une place centrale à l'organisation: Administrer c'est prévoir, organiser, commander, coordonner et contrôler.

Toute cette démarche aboutit à l'affirmation d'un principe central pour la direction des organisations, le PODC (planifier, organiser, diriger, contrôler), principe qui est demeuré un des credo dominants du discours sur l'organisation et le management. L'organisation s'entendant, dans la terminologie fayolienne, comme la constitution du double organisme, matériel et social, de l'entreprise, en d'autres termes la recherche d'une meilleure adéquation entre le versant technique et technologique de l'entreprise (machines, procédures, etc.) et son versant social (constitution et fonctionnement des groupes de travail). Tout comme chez Taylor, ses travaux aboutissent à la rédaction d'un ouvrage publié en 1916, Administration industrielle et générale, qu'on peut à juste titre considérer comme une autre production fondatrice de l'analyse des organisations, à l'instar de celle de F. W. Taylor rappelée ci-dessus.

Par ce travail, H. Fayol a bien élucidé les composantes organiques et structurelles de l'organisation tout en soulignant les fonctions essentielles que 
ces dernières assument pour garantir une plus grande cohésion dans le fonctionnement de l'organisation. Il a également relativisé l'importance, jusque-là grandissante, des dimensions technique, commerciale et financière de l'organisation. On peut risquer l'affirmation qu'on lui doit le renforcement dans les organisations modernes de la fonction administrative dont l'évolution et la transformation ont permis l'émergence de la fonction personnel, puis de ce qu'il est convenu aujourd'hui d'appeler la fonction ressources humaines. Une telle vision de l'organisation, de par sa structuration et son fonctionnement, pêche principalement par la position centrale dominante qu'elle reconnaît au dirigeant au sommet. Ce dernier apparaissant un peu comme un personnage omniscient et omnipotent entretenant ce que D. Reid (1986, p. 92) perçoit comme étant bien une idéologie autovalorisante du directeur.

\section{$L$ 'analyse de la bureaucratie administrative}

Cette dernière découle d'une vision de l'organisation qui s'inscrit un peu dans la continuité de celle décrite plus haut. On doit au sociologue et philosophe allemand Max Weber (1864-1920) la toute première tentative formelle d'analyse des organisations, du point de vue de la bureaucratie. Ses travaux, publiés en Allemagne au tournant du siècle dernier, n'ont malheureusement été accessibles dans le reste du monde qu'à partir des années trente. De manière générale, ces travaux s'orientent vers 1'étude des conditions historiques, économiques et anthropologiques de l'évolution des sociétés occidentales (travaux qui témoignent du grand intérêt de l'auteur pour tout ce qui concerne les problèmes d'organisation et de rationalisation). De toute sa production fort abondante et variée, on retiendra surtout ici son célèbre ouvrage Economie et société dans lequel il aborde largement les problèmes de fonctionnement des organisations. Sa démarche consiste d'abord à rechercher des catégories analytiques susceptibles d'expliquer la genèse et l'évolution des phénomènes sociaux dans les organisations humaines. Ces catégories analytiques qui s'apparentent à des constructions conceptuelles sont appelées des types-idéaux, c'est-à-dire des références théoriques permettant d'étudier le fonctionnement d'une organisation. Un des phénomènes qui retient davantage son attention est le fondement et le mode d'exercice de la domination. Les leçons tirées de l'évolution des sociétés, dans différentes régions du monde, le conduisent à élaborer une typologie des formes de domination (charismatique, traditionnelle et légale). Contrairement aux deux premières, la domination légale se caractérise par la consécration des règles de droit et d'un certain nombre de principes directeurs : l'obéissance à la fonction, la hiérarchie, la compétence, le contrat écrit, la qualification professionnelle, la rémunération équitable suivant la fonction exercée, le privilège de cette dernière par rapport à d'autres activités, le plan de carrière, la démarcation entre les ressources privées de l'individu et celles que l'organisation met à sa disposition pour accomplir sa fonction, la discipline et le contrôle. Par ailleurs, la domination 
légale s'exerce dans le cadre d'une forme d'organisation bien déterminée, la direction administrative et bureaucratique (M. Weber, 1971, p. 226). Cette dernière étant structurée et guidée par les principes ci-dessus en vue d'atteindre une plus grande efficacité productive.

M. Weber ne s'est pas contenté seulement de relever les avantages d'un tel modèle de rationalisation de l'organisation. Il en a également souligné quelques-unes des limites susceptibles de réduire l'efficacité recherchée. On notera principalement cette mise en garde concernant les abus de l'impersonnalisation des fonctions et du formalisme. De tels abus peuvent se traduire par l'inclination des fonctionnaires à traiter dans un sens matériel et utilitaire les tâches d'administration qui sont les leurs au service du bonheur des administrés ... (M. Weber, 1971, p. 231). On le sait, cette critique de la bureaucratie administrative, initialement développée par $M$. Weber lui-même, a été reprise et approfondie par plusieurs continuateurs (R. K. Merton, 1936, 1940; P. Selznick, 1949; A. W. Gouldner, 1954; M. Crozier, 1963). De manière générale, leurs réflexions tournent toutes autour de la très forte probabilité de voir la structure bureaucratique produire elle-même les germes de son dysfonctionnement, de son blocage, voire de son éclatement. Cela étant possible du fait de la récurrence des conséquences inattendues (R. K. Merton, 1936) ou encore des effets pervers (M. Crozier, 1963).

\section{La perspective néo-rationaliste et réformiste}

La perspective rationaliste et fonctionnaliste a beaucoup et longtemps marqué l'analyse des organisations. Elle a ouvert la voie à d'autres courants s'inscrivant dans une vision critique du discours dominant sur les organisations. Mais en réalité, plusieurs de ces courants ont plus ou moins puisé dans ce même discours quoiqu'ils aient cherché à s'en démarquer, du moins dans leur énoncé théorique. C'est notamment le cas des courants que O. Aktouf (1990a) range dans la perspective néo-rationaliste et réformiste: 1'analyse de la prise de décision et la description du travail du dirigeant ainsi que de la structure organisationnelle.

\section{$L$ 'analyse de la prise de décision}

C'est au cours des années cinquante et soixante qu'apparaissent les premiers jalons d'une réflexion profonde sur les problèmes de prise de décision dans les organisations. Le contexte d'alors en Occident est celui de la reconstruction économique d'après-guerre, doublée de l'expansion à travers le reste du monde des méthodes de gestion héritées de la vision fonctionnaliste et rentabiliste de l'organisation, telle que développée par les pionniers F. W. Taylor, H. Fayol et M. Weber. Ce nouvel élan économique entraîne un perfectionnement notable des techniques de production et de gestion. On assiste notamment à l'introduction dans l'entreprise de l'outil informatique dont les capacités 
phénoménales d'analyse et de traitement des données en font un instrument privilégié de résolution des problèmes. Par ailleurs, c'est aussi une période marquée par l'émergence des graves conflits militaro-idéologiques dont l'issue a failli changer la face du monde ${ }^{5}$. C'est dans ce contexte que Herbert Simon s'intéresse à un élément essentiel dont il va faire une dimension centrale dans le fonctionnement des organisations: la décision et les mécanismes qui concourent à son élaboration (H. Simon, 1960, 1980). Pour lui, on ne peut pas bien appréhender la dynamique des comportements organisationnels sans chercher à comprendre la démarche qui amène un individu à prendre telle ou telle décision face à un problème déterminé. Comme le souligne $O$. Aktouf (1989a, p. 233) dans le commentaire qu'il fait des travaux de Simon, le choix ou la décision se font donc dans un contexte et dans le cadre d'un processus qui relèvent souvent beaucoup plus des façons habituelles de fonctionner que d'analyses exhaustives et rationnelles: ce choix ne peut être la meilleure décision, mais seulement la plus satisfaisante, dans les circonstances, parmi plusieurs options possibles ${ }^{6}$.

En somme, l'individu qui prend une décision devant une situation a tout à fait tort de croire qu'il a réuni tous les ingrédients nécessaires et que la décision prise est la seule qui peut permettre la résolution effective du problème auquel il est confronté. Cette précision est de taille dans la mesure où elle permet de bien mesurer la relativité d'une décision, et donc ses limites quant à permettre la résolution du problème. Quelque que soit la décision prise, elle ne saurait être considérée comme la meilleure de manière absolue ; mais simplement comme celle qui s'avère la plus satisfaisante pour la personne qui la prend et compte tenu du contexte à ce moment précis. C'est ainsi qu'on retrouve au coeur de l'analyse de la prise de décision le concept fondamental de rationalité limitée (H. A. Simon et J. G. March, 1958). L'ensemble de ses travaux sur l'analyse de la prise de décision a d'ailleurs valu à $H$. Simon une récompense de taille, par l'attribution du Prix Nobel de Science Economique en 1978.

Ces travaux, dont les principaux mérites résident dans l'analyse des fondements psychologiques ainsi que dans la démonstration de la relativité des processus de prise de décision, et donc des choix que l'on est amené à faire dans la vie, n'ont pas manqué de soulever quelques critiques de fond. Une des principales critiques a été faite par L. Urwick (1965), un des représentants du paradigme fonctionnaliste classique d'inspiration fayolienne. De manière générale, $\mathrm{H}$. Simon reproche aux ténors de ce paradigme leur vision rationnelle excessive du fonctionnement de l'organisation. C'est tout le sens qu'il entend bien donner à son concept de rationalité limitée. Cependant, il persiste à voir dans l'ordinateur un support déterminant voire un outil quasi magique de la prise de décision (H. A. Simon, 1980). Une telle approche risque bien de rendre l'individu en situation de prise de décision prisonnier de la rationalité instrumentale et mécanique qui est par ailleurs dénoncée par H. Simon. Dans ces conditions, on est fondé de penser que la rationalité limitée énoncée par $H$. 
Simon pour remettre en cause la rationalité organisationnelle défendue par $F$. W. Taylor, H. Fayol et M. Weber, aurait bien du mal à s'accommoder de la rationalité décisionnelle (O. Aktouf, 1989a, p. 235) qui se dégage de ses analyses.

\section{$L$ 'analyse descriptive du travail du dirigeant}

Ce courant apparaît au début des années soixante-dix à partir d'une tentative de H. Mintzberg (1973) de comprendre le travail des dirigeants dans les organisations. Il s'est agi pour l'auteur de voir dans quelles mesures les dirigeants arrivaient à appliquer, dans leur travail quotidien, les sacro-saints principes de l'organisation énoncés par H. Fayol et qui se résument au PODC (planifier, organiser, diriger, contrôler). Pour ce faire, H. Mintzberg n'a pas hésité à partager le temps de travail de cinq dirigeants dans le but d'analyser leur travail quotidien de manière méthodique et rigoureuse. Cette expérience, pour laquelle il a abondamment eu recours à la méthode de l'enquête monographique, l'a conduit à faire un certain nombre de constats très intéressants sur le travail quotidien du dirigeant. De manière schématique, ce travail présente un certain nombre de caractéristiques principales:

- activités peu structurées;

- activités plus réactives et moins proactives;

- activités accordant une place centrale aux processus d'information et de communication;

- activités exercées de manière très souvent polychrone, c'est-à-dire que les problèmes ne sont pas traités de façon absolument séquentielle et ordonnée (plusieurs problèmes sont traités à la fois);

- activités interactives qui mettent le dirigeant dans une position d'intermédiation entre les différents acteurs internes et externes de l'entreprise.

L'accomplissement de ces activités par le dirigeant l'amène à assumer plusieurs rôles dont $\mathrm{H}$. Mintzberg identifie principalement trois: les rôles interpersonnels, informationnels et décisionnels ${ }^{7}$. H. Mintzberg (1979) poursuit sa démarche d'analyse descriptive des activités du dirigeant, ainsi que des conditions de son exercice, en s'intéressant davantage à la structuration et au fonctionnement des organisations. Ces dernières sont analysées suivant un certain nombre de paramètres essentiels: les éléments de base constitutifs, les flux organisationnels, les mécanismes d'interaction et de coordination, la typologie organisationnelle, les agents inducteurs du changement.

L'analyse descriptive de l'organisation proposée par H. Mintzberg (aussi bien sous l'angle de la description factuelle des activités du dirigeant que de celui de la description de la structure dynamique organisationnelle) a permis de révéler les écarts entre ce qu'est supposé faire un dirigeant (ou qu'il croit faire) et ce qu'il fait effectivement. En somme, on arrive par cette démarche à 
percevoir la distance entre les principes régissant le fonctionnement des organisations et les pratiques observées chez les individus. Toutefois, cette approche présente un certain nombre de limites qu'on ne saurait occulter. En se focalisant essentiellement sur le travail du dirigeant, $H$. Mintzberg adopte une posture qui le conduit inéluctablement à appréhender le fonctionnement d'une organisation principalement du point de vue du dirigeant au sommet (le Top Manager). Sa vision privilégie l'organisation au sommet même si la structure organisationnelle qu'il définit fait ressortir les niveaux intermédiaires et inférieurs (ligne hiérarchique, appui logistique). Au fond, $H$. Mintzberg semble évoluer dans une position assez paradoxale à la fois de remise en cause et de légitimation des principes d'organisation énoncés avant lui par $\mathrm{H}$. Fayol et fondés sur une vision un peu trop fonctionnelle de l'organisation. La position de remise en cause apparaît à travers l'écart voire la rupture qu'il montre entre l'énoncé théorique et la pratique quotidienne concernant le travail du dirigeant; ce qui révèle bien les limites d'une organisation qui se veut rationnelle et fonctionnelle. Quant à sa position de légitimation, elle transparaît dans la valorisation de la figure dominante du dirigeant; ce dernier étant présenté comme l'acteur central de l'organisation. Sur ce dernier point, il rejoint tout à fait les classiques dont on a parlé plus haut. On peut enfin se demander, comme le fait O. Aktouf (1989a), si une forte tentation à la structuration de l'organisation ne risque pas de provoquer davantage de formalisme et de rapprocher $\mathrm{H}$. Mintzberg des théoriciens classiques de l'organisation dont il entend pourtant se démarquer de la vision prescriptive et normative.

\section{La perspective organiste et systémique}

Cette dernière puise abondamment dans les sciences biologiques et physiques, et entend établir un parallèle entre l'organisation en tant que corps social et l'organisme vu comme une structure biologique. C'est une perspective qui permet d'analyser l'organisation à partir d'une analogie entre le biologique et le social. Cette tentative de lecture biologique de l'organisation sociale est fort ancienne puisqu'on retrouve déjà les prémices chez H. Spencer (1876), dans l'énoncé qu'il fait des principes de sociologie. La question demeure d'actualité et suscite encore de nos jours un vif débat interdisciplinaire (Collectif, 1977). L'analogie entre le biologique et le social vise principalement à montrer que, comme tout corps vivant, l'organisation sociale connaît une activité interne résultant de la synergie de ses différentes composantes. Par ailleurs, cette activité $s$ 'articule autour de ses différentes phases de croissance et lui permet de s'adapter à son environnement; adaptation qui est essentielle à sa pérennité. Nous évoquerons cette perspective à travers ses deux courants représentatifs: le courant systémique et le courant socio-technique. 


\section{L'analyse systémique de l'organisation}

Par rapport à ce qui vient d'être dit, il n'est donc pas surprenant que l'analyse systémique de l'organisation soit au départ tributaire des recherches biologiques, en particulier celles de L. Bertalanffy (1973). Cependant, il convient de relever que ce dernier est parti d'une vision biologique et physique de l'organisation pour en proposer une autre beaucoup plus élargie et intégrant plusieurs autres disciplines du champ des sciences sociales (psychologie, sociologie, philosophie). C'est bien là le point de départ de la théorie générale des systèmes qu'il a développée et qui sert de base à l'analyse systémique. Pour simplifier, disons que cette dernière considère l'organisation comme une structure sociale vivante, constituée de plusieurs éléments assurant des fonctions complémentaires; structure en permanence ouverte sur l'environnement extérieur. De ce point de vue, l'organisation n'est pas simplement un système mais un système ouvert qui entretient avec son environnement une relation dont on peut dire qu'elle fonctionne suivant le principe des vases communicants, au sens de la recherche d'un équilibre entre l'organisation et l'environnement. La première reçoit du second des inputs (intrants) qu'elle transforme et qu'elle lui renvoie comme des outputs (extrants). Une illustration simple. L'entreprise installée dans un environnement reçoit de ce dernier (à travers les fournisseurs) toutes sortes d'éléments nécessaires à son activité, parmi lesquels notamment des matières premières et des produits bruts. Ces derniers subissent une transformation interne et sont reversés sur le marché (chez les clients) sous forme de produits finis destinés à la consommation.

Avec G. Morgan (1989, pp. 39-44), on a une formulation générale de l'approche systémique de l'organisation. C'est d'abord la reconnaissance du rôle déterminant de l'environnement dans lequel se trouve l'organisation; ce qui met en évidence la force du lien interactif entre cette dernière et son environnement. C'est ensuite l'existence au sein même de chaque organisation de plusieurs composantes ou sous-systèmes tout à fait interdépendants; l'activité de chaque sous-système ayant des incidences sur celle des autres. C'est enfin la nécessité de considérer que les différents sous-systèmes ne s'excluent pas; bien au contraire ils se complètent et c'est cela qui permet le fonctionnement de l'ensemble du système organisationnel.

L'analyse systémique, telle qu'elle vient d'être survolée, permet de mettre en évidence l'influence déterminante de l'environnement sur le fonctionnement de l'organisation. On ne saurait comprendre ce qui se passe à l'intérieur sans se référer à ce qui se passe à l'extérieur. Cela semble plus qu'évident à première vue. Cependant, dans quelle mesure l'environnement externe est-il susceptible d'agir sur la dynamique organisationnelle? Là est la question que certains, à l'instar de H. Maturana et F. Varela (1980) n'ont pas manqué de se poser pour remettre en cause la théorie des systèmes ouverts. Pour eux, l'organisation ne saurait être analysée comme un système vivant ouvert mais plutôt fermé. Cette fermeture traduit la capacité des systèmes à 
fonctionner de manière autonome et à chercher à conserver une identité en subordonnant tous les changements au maintien de leur propre organisation en tant qu'ensemble de relations particulier (G. Morgan, 1989, p. 273). De cette critique pertinente de la théorie générale des systèmes, nous pouvons tirer un enseignement utile pour aborder l'analyse des organisations: l'organisation doit davantage être analysée comme un système à la fois fermé (nécessité de préserver un minimum de valeurs identitaires et institutionnelles) et ouvert (nécessité de s'adapter au changement ambiant). Cela découle tout naturellement de la double dynamique de décomposition et de recomposition qui est au cœur du changement social. De manière tout à fait métaphorique, on peut risquer l'affirmation que le discours sur le système ouvert ou fermé ressemble bien à celui sur la bouteille à moitié pleine ou à moitié vide. Résumons cela en disant qu'en réalité, toute organisation a tendance à se fermer en même temps qu'elle cherche à s'ouvrir en fonction de sa capacité à gérer les contraintes diverses qu'elle subit de son environnement et qui sont susceptibles d'ébranler son fonctionnement. Ce dernier obéit à un mouvement ambivalent de fermeture-ouverture.

\section{L'analyse socio-technique de l'organisation}

Ce courant partage bien des points communs avec le courant systémique qui vient d'être présenté. Il a vu le jour à partir des années cinquante, suite à une série de recherches empiriques sur les changements technologiques dans la production du charbon, dans les mines britanniques. Ces recherches ont été menées dans le cadre d'un institut (Tavistock Institute de Londres) devenu célèbre pour la contribution de ses chercheurs à la compréhension des problèmes liés au fonctionnement des organisations (E. L. Trist et K. W. Bamforth, 1951). Ces chercheurs se sont principalement intéressés à la réorganisation du travail des mineurs, suite à l'introduction de nouvelles technologies ayant permis le passage d'un système élargi de production par groupes autonomes à un système de production beaucoup plus spécialisé et supposé plus performant que l'ancien. Naturellement, le but visé par ce changement technologique était d'améliorer la performance des mineurs. Ces derniers n'ont malheureusement pas réagi comme prévu, puisqu'on a finalement observé chez eux une baisse sensible de la performance accompagnée d'une désaffection au travail. De telles conclusions, à priori surprenantes, et qui rappellent un peu celles auxquelles est parvenu E. Mayo vingt années plus tôt lors de ses expériences à la Western Electric Company de Chicago ${ }^{8}$, ont apporté un éclairage nouveau sur le rapport entre le versant social et le versant technique du travail. C'est donc l'analyse de ce rapport qui s'est poursuivie par la suite à travers une démarche socio-technique que C. Levy-Leboyer (1974, p. 34) présente comme un schéma de variables où ily a interdépendance mutuelle entre la dimension technique du travail (ses exigences, ses conditions matérielles, la nature des produits traités, l'équipement technique...) et sa 
dimension sociale (les relations interpersonnelles, la taille des équipes, les compétitions intergroupes...).

L'analyse socio-technique part donc d'une vision bipolaire de l'organisation considérée à travers deux sous-systèmes dominants: d'une part celui des structures, des procédures, des techniques, etc.; d'autre part celui des personnes, de leurs états émotifs, des liens et des réseaux dans lesquels elles fonctionnement, etc. Le principe régulateur d'un tel schéma est qu'on ne peut agir sur l'un des éléments constitutifs d'un sous-système sans que cela n'ait des incidences sur un ou plusieurs élément(s) de l'autre sous-système. C'est une approche intéressante dont le mérite principal réside dans la redéfinition du rapport entre l'individu et l'outil de production, ainsi que dans la facilitation des modalités d'insertion de l'individu dans le système productif. Par ailleurs, elle se traduit par la recherche d'une intégration harmonieuse et fonctionnelle de différents paramètres (sociaux et structurels) concourant à l'activité de l'organisation. Reste qu'à force de se focaliser uniquement sur les deux composantes (sociale et technique) de l'organisation, l'analyse socio-technique réduit en quelque sorte le champ organisationnel à ces deux composantes. Ce qui est loin d'être évident comme le montrent notamment Kast et Rosenzweig (1973) et surtout G. Morgan (1989, p. 45). Ce dernier propose un schéma organisationnel plus global intégrant plusieurs sous-systèmes (sous-système technique, sous-système humain-culturel, sous-système structurel, sous-système de gestion, sous-système stratégique). Ces différents sous-systèmes étant tous regroupés au sein d'un suprasystème environnemental.

\section{La perspective actionnaliste et stratégique}

Cette dernière a connu une période de développement au cours des années soixante et soixante-dix, principalement en France et dans les pays latins longtemps marqués par une tradition sociologique marxiste. Elle considère l'action sociale et les significations que chaque sujet lui donne comme le fondement de toute conduite humaine. Au centre de toute cette démarche, il y a les acteurs sociaux, leurs attentes, les conflits auxquels ils sont confrontés et les stratégies qu'ils développent à cet effet. Ces conflits et ces stratégies ont pour principal enjeu l'exercice et le contrôle du pouvoir. Deux courants importants peuvent être rangés dans cette perspective: celui de l'analyse des mouvements sociaux et celui de l'analyse stratégique du pouvoir.

\section{L'analyse actionnaliste des mouvements sociaux}

On doit cette tradition d'études au sociologue français A. Touraine (1963) dont les travaux ont permis une meilleure compréhension des mouvements sociaux et des significations que les acteurs concernés leur donnent. Ces mouvements sociaux sont au cœur de l'histoire et jouent un rôle central dans la production de 
la société (A. Touraine, 1973). De ce point de vue, l'analyse de l'organisation doit partir du principe fondamental que cette dernière est le produit d'un contexte historique donné dont il convient de bien élucider les contours. $\mathrm{Ce}$ contexte est abondamment marqué par les conflits sociaux qui sont eux-mêmes révélateurs des rapports de classe et de domination entre les groupes sociaux. L'organisation devient en quelque sorte le miroir de la société. Ce qui s'y produit ne l'est pas fortuitement, mais résulte d'un ensemble de facteurs historiques dont on ne peut faire abstraction dans l'analyse des organisations. Ce schéma théorique a été appliqué à l'étude de plusieurs événements sociaux se traduisant par des conflits et des crises dans différents secteurs de la société, en particulier dans l'institution universitaire et dans le monde du travail (A. Touraine, 1978; 1982; 1984).

L'analyse actionnaliste permet donc de mettre en évidence la dimension historique qui est déterminante dans le fonctionnement des organisations. Elle nous rappelle que l'organisation est une réalité qui se construit et se reconstruit au jour le jour. Elle permet aussi de faire le lien entre les faits organisationnels et les faits sociaux. On peut cependant se demander si la personnification des mouvements sociaux qui se dégage de cette doctrine n'est pas de nature à rendre l'organisation prisonnière de son histoire et des conflits sociaux qui l'ont marquée, et donc peu susceptible de s'ouvrir à l'innovation et au changement.

\section{$L$ 'analyse stratégique du pouvoir}

C'est avec M. Crozier (1963) et E. Friedberg (1971) qu'on assiste aux débuts de l'élaboration formelle des principes de base de l'analyse stratégique de l'organisation. Si le courant stratégique partage avec le précédent au moins un point commun (la vision de l'organisation en mouvement dans un champ conflictuel), il s'en démarque considérablement en remettant en question toute idée de déterminisme social ou historique. A l'approche macro-sociologique du courant actionnaliste (dynamiques sociales collectives), le courant stratégique oppose une approche micro-sociologique davantage centrée sur l'étude des dynamiques internes au sein de l'organisation. Parmi celles-ci, une est particulièrement importante: la dynamique du pouvoir analysée à travers les enjeux du pouvoir et le jeu des acteurs du pouvoir.

M. Crozier et E. Friedberg (1977) voient dans la dynamique du pouvoir le dénominateur commun à toutes les organisations. Le pouvoir est surtout analysé comme une relation qui n'est pas du tout fígée, mais qui se construit en permanence suivant les projets, les objectifs (avoués ou non) des protagonistes présents sur le champ organisationnel. Ces derniers, appelés acteurs, ont tous des possibilités d'exercer le pouvoir quelque soit leur position hiérarchique. Au fond, chacun des acteurs est susceptible de détenir et de contrôler une parcelle de pouvoir aussi petite soit-elle. L'exercice de ce pouvoir se fait à travers un mécanisme social qui ressemble fort à un jeu auquel se livre les différents 
protagonistes. L'issue finale du jeu dépendra fortement de la capacité de chacun des protagonistes à détecter et à contrôler les sources du pouvoir (spécialisation et compétence professionnelle, contrôle de l'environnement, connaissance et maîtrise des circuits d'information, utilisation et interprétation des règles organisationnelles). Par ailleurs, au cours de ce jeu organisationnel autour du pouvoir, chacun des protagonistes cherche absolument à créer et à contrôler des situations d'imprévisibilté (des zones d'incertitudes); ce qui lui confère un certain nombre d'avantages compétitifs sur les autres protagonistes. Avantages dont il cherche à tirer profit pour renforcer son pouvoir aux dépens des autres protagonistes.

L'analyse stratégique du pouvoir trouve sa pertinence dans le fait que le pouvoir ne saurait être considéré seulement comme l'affaire d'une catégorie déterminée de personnes (les élites ou les chefs hiérarchiques, par exemple). C'est l'affaire de tous, que l'on soit supérieur ou subordonné. C'est une ressource essentielle à laquelle chacun, parce que disposant d'une autonomie d'action relative, peut avoir accès pour peu qu'on arrive à connaître et à développer les atouts divers dont on est tous porteur. Par ailleurs, cette démarche stratégique apporte encore un éclairage de plus sur l'importance des non-dits, très nombreux et très déterminants dans le fonctionnement des organisations. On lui reprochera toutefois de s'inscrire dans une vision quelque peu synchronique de l'organisation, qui fait que l'analyse des stratégies d'acteurs ne tient pas beaucoup compte de l'évolution dans le temps. Ces stratégies ne sauraient par ailleurs être appréhendées en dehors des rapports sociaux collectifs.

\section{La perspective humaniste et culturaliste}

Cette perspective témoigne de l'intérêt grandissant, chez les théoriciens des organisations, d'un certain nombre de dimensions longtemps marginalisées et pourtant essentielles. En effet, loin d'être un simple agrégat de personnes évoluant dans un système automatique ou mécanique, l'organisation est avant tout un corps social dont les membres pensent et agissent avec leurs racines sociales, leurs traits de caractère, leurs états émotifs, etc. Ce sont autant de variables importantes dont la prise en compte, dans les différentes perspectives précédentes, a été plus ou moins effective. C'est donc à ces dimensions que s'ouvrent progressivement les recherches sur le fonctionnement des organisations, comme le soulignent bien J.-F. Chanlat et coll. (1990) dans le tour d'horizon qu'ils font des dimensions oubliées de l'organisation. Cette perspective a pour principal centre d'intérêt la personne humaine, son développement et son épanouissement dans l'organisation. Elle reconnaît par ailleurs une place centrale aux facteurs socioculturels susceptibles de contribuer à cet épanouissement. Les principaux courants pouvant être rattachés à cette perspective ont été développés à des périodes différentes, autour du même fil conducteur: la reconnaissance à la fois de la relativité et de la complexité de 
l'être humain dans les organisations. Nous commencerons cette présentation par un regard rétrospectif sur ce qui nous semble être le courant fondateur des analyses sur l'être humain en milieu organisationnel (le mouvement des relations humaines). Puis on s'intéressera à différents autres courants qui mettent en évidence le rapport entre l'individu, l'organisation et l'environnement socioculturel. Il s'agit notamment des courants interculturel, culturel et psychodynamique.

\section{$L$ 'analyse des « Relations humaines 》}

Le début des années trente voit l'émergence du discours sur les Relations humaines dans les organisations. Ce dernier n'est pas fondamentalement en contradiction avec le discours antérieur et persistant sur la formalisation et la rationalisation de l'organisation, en vue d'une plus grande rentabilité financière. Au fond, il s'agit moins de remettre en cause cette dernière finalité que de voir par quels moyens parvenir à un « adoucissement » des modalités de sa réalisation qui demeure un objectif essentiel. La pertinence de cette approche de l'organisation en termes de structure humaine et sociale se justifie à partir d'un constat majeur: 1'évolution des conditions matérielles et financières du travail ne suffit pas pour améliorer la productivité et la satisfaction des travailleurs. Ce que les théoriciens d'organisation et du management ont consacré sous l'appellation effet Hawthorne ${ }^{9}$, à la suite des expériences fort célèbres conduites par E. Mayo (1880-1949), peut se résumer ainsi: dans la vie professionnelle, et de manière générale dans la vie en société, la dimension socio-affective est toujours présente et il faut bien pouvoir composer avec elle, car elle constitue un élément déterminant de l'engagement et de la mobilisation des personnes.

C'est à l'usine Hawthorne de la Western Electric Company à Chicago que Elton Mayo et son équipe de chercheurs ont réalisé, entre 1923 et 1927, une série d'expériences sur le rapport entre les conditions de travail et la productivité des travailleurs fabriquant du matériel téléphonique. Ces expériences ont attiré l'attention sur un certain nombre de préoccupations relatives au comportement de ces travailleurs. Sans chercher à faire une présentation détaillée de ces différentes expériences, on peut simplement retenir qu'elles avaient pour objectif principal d'expliquer les origines de la lassitude professionnelle et de la baisse de la productivité chez des groupes d'ouvriers soumis à des tâches monotones et contraignantes. Les expériences ont permis de constater que, dans certaines équipes de production dont les conditions de travail étaient plus éprouvantes (difficultés d'éclairage, variation des horaires et de la durée de la pause, etc.), l'engagement des travailleurs était maintenu voire accentué et leur productivité en constante amélioration. L'explication de cette situation, à première vue paradoxale, réside dans la possibilité pour ces travailleurs de développer, au sein de leur équipe de production, une vie interne fondée sur des normes de sociabilité, d'altérité, de 
reconnaissance mutuelle. Dans ce cas, la productivité des travailleurs est beaucoup plus déterminée par les facteurs liés à la vie en communauté à l'intérieur du groupe que par les conditions matérielles et financières du travail. A la suite d'E. Mayo, cette approche du fonctionnement de l'organisation a été reprise et enrichie par différents auteurs dont $\mathrm{K}$. Lewin ${ }^{10}$ qui a mis en évidence l'effet déterminant de la dynamique de groupe sur les comportements individuels et le changement social.

En définitive, l'analyse des organisations suivant le courant des relations humaines a davantage permis de comprendre les limites de la matérialité et de l'instrumentalité de l'organisation, même si elle n'a véritablement pas proposé une vision totalement différente de la vision dominante à l'époque. Elle a par ailleurs montré l'importance, au sein des organisations, des questions relatives à la subjectivité et à l'informalité des comportements. Avec le recul du temps, on comprend mieux pourquoi les problèmes de comportement ont occupé une place grandissante dans l'enseignement et dans la pratique du management ${ }^{11}$.

\section{L'analyse interculturelle de l'organisation}

Ce courant, tout comme le courant culturel dont il va être question ci-dessous, met principalement l'accent sur la diversité des traditions et des pratiques sociales dans le fonctionnement des organisations. Ces dernières, comme dirait G. Morgan (1989, p. 144), devant être essentiellement considérées comme des réalités socialement construites, dont les points d'ancrage sont autant dans la tête de leurs membres que dans des ensembles concrets de règles et de relations. Au cœur de l'analyse (inter)culturelle de l'organisation, il y a donc la culture; concept galvaudé et polémique qui a d'abord été élaboré dans les milieux anthropologiques avant d'être repris en sociologie et en management.

Avant de clarifier les fondements et les mécanismes de l'analyse interculturelle, il est utile de préciser très rapidement les contours et le contenu de ce concept. Cela permettra de mieux comprendre pourquoi et comment son usage s'est renforcé dans les champs disciplinaires évoqués ci-dessus. Tournons-nous encore une fois vers G. Morgan (1989, p. 120) dont l'analyse de la culture au double plan de la sociologie des organisations et du management est intéressante: Quand nous parlons de culture, nous faisons en général allusion au modèle de développement que reflète, dans une société, son système de connaissance, son idéologie, ses valeurs, ses lois et le rituel de tous les jours. Ainsi définie, on peut globalement dire que la culture fait penser aux traditions sociales, aux représentations dominantes ou émergentes, aux normes implicites et explicites, à tout ce qui permet aux membres d'une communauté humaine de donner un sens à leur existence. Tout ceci devant être appréhendé dans un cadre dynamique et constructiviste (les éléments constitutifs de la culture se créent et se recréent au quotidien, suivant les formes de contraintes qui s'exercent sur les membres d'une communauté). Dans le prolongement de cette approche socio-anthropologique et managériale de la culture, O. Aktouf(1990, 
pp. 560-565) propose quelques éléments essentiels qu'il convient de rappeler: ensemble complexe et multidimensionnel de ce qui fait la communauté de vie dans les groupes; interdépendance entre histoire, structure, conditions de vie et vécu subjectif des personnes; ensemble d'éléments en rapports dialectiques constants; système d'oppositions ou de clivages au sein d'une même communauté; complexe collectif de "représentations mentales " liant l'immatériel et le matériel; action d'éléments constitutifs universels notamment le mythe. Ce bref rappel nous conduit maintenant à voir plus concrètement comment le concept de culture a été repris dans l'analyse des organisations.

Dans l'analyse interculturelle de l'organisation, la culture apparaît davantage comme une variable externe à l'organisation ${ }^{12}$, c'est-à-dire que la culture s'élabore en dehors de l'organisation qui est elle-même ancrée dans un environnement social déterminé. Du fait de la diversité des modes de vie dans les différentes sociétés humaines à travers le monde, les notions de différenciation et de relativité deviennent ici essentielles. De manière générale, on peut voir dans la démarche interculturelle trois phases principales: partir de ce qui se fait au sein d'une organisation déterminée (la manière dont les membres se comportent devant une situation donnée), tenter de faire le lien avec les formes de conduites dominantes ou émergentes dans le reste de la société, rechercher et analyser des situations similaires dans d'autres sociétés ailleurs dans le monde. En somme, l'analyse interculturelle se propose de dégager et d'expliquer le rapport entre une organisation, sa société de référence, les autres sociétés. Dans le domaine du management par exemple, cette démarche a connu beaucoup de succès au cours des années soixante-dix. On a eu recours à l'analyse interculturelle, connue sous le nom de Comparative Management (R. A. Webber, 1969), pour tenter une comparaison (à partir du modèle américain) des principes et des pratiques de management dans différentes régions du monde. Les théoriciens et les praticiens du management ont été beaucoup fascinés par le formidable succès des entreprises japonaises, aussi bien au Japon qu'ailleurs dans le monde, malgré la pauvreté relative de ce pays en ressources minières et naturelles. La principale explication retenue a bien été celle de la prééminence des traditions nationales japonaises dans la structuration et le fonctionnement des organisations économiques. A la faveur de la mondialisation dominante actuelle, le courant interculturel continue de susciter beaucoup d'intérêt sur la base d'expériences diverses et variées (W. G. Ouchi, 1982; R. T. Pascale et A. Athos, 1984; D. Bollinger et G. Hofstede, 1987; Ph. d'Iribarne, 1989 et 1998). Ce dernier courant est émergent en Afrique où l'on est, en ce moment, très profondément préoccupé par la recherche de modèles d'organisation susceptibles de concilier l'efficience productive et la sociabilité communautaire (H. Bourgoin, 1984 ; Collectif, 1996; D. Mercure, 1997; E. Kamdem, 1996a, b, c, 1999; J.-P. Warnier, 1993; M. Zadi Kessy, 1998). Ce point sera développé dans la partie suivante. 
L'analyse interculturelle a permis la redécouverte et la réhabilitation des traditions nationales dans certains pays longtemps fermés à l'influence extérieure (Japon), ou encore longtemps marginalisés et dominés (Afrique). Elle a été d'une grande utilité pour la compréhension de la relativité des pratiques culturelles à travers le monde. On lui a beaucoup reproché (parfois avec raison) sa vision un peu trop culturaliste des problèmes sociaux, à savoir chercher à tout expliquer (succès ou échec) par la force des phénomènes culturels plus que par celle des structures et des institutions sociales. De ce point de vue, l'analyse interculturelle est porteuse d'une tentation ethnocentrique et dominatrice; car les cultures supposées plus performantes économiquement peuvent finir par $s$ 'ériger en cultures de référence aux dépens des autres. C'est bien cela la source du discours fondateur d'un certain nombre de mouvements historiques subis par certains peuples, notamment africains (traite des esclaves noirs, colonisation occidentale, recrudescence des guerres ethno-tribales en période de mondialisation économique et politique). La polémique autour de la pertinence des thèmes de la culture et de l'interculturel dans l'organisation est abondamment analysée par différents auteurs dans des publications récentes (J.-F. Bayart, 1996; Ph. d'Iribarne, 1992; M. Maurice, 1989).

\section{L'analyse culturelle de l'organisation}

Ce courant traite la culture essentiellement comme une variable interne à l'organisation. C'est à partir des années quatre-vingt qu'on voit se développer de manière systématique, surtout dans les milieux gestionnaires nord-américains, un intérêt pour la culture comme instrument de gestion. Le problème est de voir comment une organisation peut réussir à produire une culture propre susceptible de soutenir la productivité individuelle et organisationnelle. Cette vision de la culture est connue sous l'appellation de Corporate culture, expression anglo-saxonne diversement traduite en français (culture corporative, culture organisationnelle, culture d'entreprise). Cette manière d'inscrire la culture au centre de l'organisation a été développée par plusieurs auteurs dont les plus connus sont T. E. Deal et A. A. Kennedy (1982); T. J. Peters et R. H. Waterman (1982). Elle a été reprise par différents autres auteurs qui ont surtout souligné sa dimension fonctionnaliste (M. Bosche, 1984; N. Lemaître, 1984; E. Schein, 1985). Mais surtout elle a été diversement critiquée pour son usage abusif dans les milieux gestionnaires (O. Aktouf, 1990; Y. Bertrand, 1991). Comment comprendre cette notion de culture organisationnelle, notion à la fois prisée et polémique ? On retiendra cette esquisse de définition générale proposée par O. Aktouf $(1990$, p. 555) qui fait une synthèse critique des principaux travaux sur la question: De prime abord, on a nettement l'impression qu'il s'agit d'un fourre-tout où s'entrecroisent et se télescopent, pêle-mêle, du leadership, des valeurs, des symboles, des mythes, des légendes, des sagas, des anecdotes, des croyances, des structures, des habitudes, des langages, des rites, des cérémonies, des règles sociales, des 
normes, des credos, des philosophies de gestion, des savoirs partagés, des leçons d'être ou de s'habiller, des déterminants inconscients, etc. Comme on le voit, le succès dans les milieux gestionnaires de la notion de culture organisationnelle ou de culture d'entreprise s'explique largement par ce fait qu'elle est davantage perçue comme regroupant une collection de recettes pour la performance économique tant recherchée par les dirigeants.

Analyser l'organisation en termes culturels a donc présenté (et continue de présenter) un avantage certain qui est de mettre l'organisation au cour de la société. De ce point de vue, l'organisation n'est pas seulement une structure matérielle mais aussi une structure symbolique, vivante, capable de produire et d'entretenir des valeurs, des normes régissant son fonctionnement et susceptibles de conduire à une intégration optimale de l'économique et du social. Vu sous cet angle et en tenant compte du changement d'époque, on peut risquer l'affirmation que le courant de la culture d'entreprise présente quelques ressemblances lointaines avec celui des relations humaines développé par $\mathrm{E}$. Mayo $^{13}$. Le cadre conceptuel et les applications de la culture d'entreprise ont suscité de très nombreuses polémiques dont le fil conducteur est l'instrumentalisation et la matérialisation de la culture. A force de rechercher la performance économique, on risque bien de « fabriquer» de manière tout à fait abstraite une culture d'entreprise qui, dans ces conditions, peut plutôt devenir un instrument d'oppression des salariés et entretenir les germes de l'éclatement de 1'entreprise. G. Morgan (1989, p. 138) a bien raison quand il écrit: On n'impose pas une culture à un groupe social. En fait, elle se développe au fil de l'interaction sociale. Certaines cultures d'entreprise, très fortes, peuvent servir au développement de structures pathologiques dont l'impact sur le comportement humain est considérable. Dans ce cas, ces cultures finissent par conduire à des résultats contraires à ceux attendus, à savoir favoriser l'exclusion et non l'intégration sociale recherchée.

\section{L'analyse psychodynamique de l'organisation}

Ce courant s'est développé, à partir des années soixante-dix, principalement autour des questions relatives à la dynamique de la réalité psychique et à la psychopathologie professionnelle dans les organisations. Dans un cas comme dans l'autre, l'organisation est analysée à partir d'une lecture psychanalytique de la personnalité des individus, de leurs comportements et surtout de leur vécu personnel de la vie organisationnelle. C'est dire que ce courant doit beaucoup aux recherches psychanalytiques qui mettent en évidence des phénomènes importants comme l'affectivité et l'émotivité. Comme le souligne J.-F. Chanlat (1991, p. 10), il s'agit d'analyser le rapport entre l'individu et l'organisation en cherchant à rendre compte de l'interaction entre le psychisme et le social dans des ensembles organisés. Sans chercher à remonter aux origines psychanalytiques de ce type de démarche (S. Freud, 1973; M. Klein, 1978), on peut, toujours avec J.-F. Chanlat (1990), dégager deux axes majeurs dans les 
travaux de ce type. Le premier porte sur la dynamique interne de la vie psychique, et le second sur le plaisir et la souffrance au travail.

Le premier axe s'est développé autour d'un certain nombre de préoccupations comme par exemple l'inconscient et l'imaginaire de groupe (D. Anzieu, 1975), l'affectivité dans les groupes (M. Pagès, 1984), la psychanalyse du lien social (E. Enriquez, 1983), la dynamique psychique des dirigeants (A. Zaleznik et M. F. R. Kets de Vries, 1975; M. F. R. Kets de Vries et D. Miller, 1985; L. Lapierre, 1992), la différenciation sexuelle dans l'exercice du pouvoir (N. Aubert; V. de Gaulejac; E. Enriquez, 1986), la psychologie du self (H. Kohut, 1985; T. Pauchant, 1990). Toutes ces préoccupations sont nées du souci des uns et des autres d'approfondir la connaissance de la dimension subjective de l'organisation. Cette dimension relève de l'intériorité que L. Lapierre (1990, p. 263), un des représentants actuels de cette tradition d'études au Canada, considère comme l'aspect le plus secret et le plus mystérieux de l'individu, dans ses composantes aussi bien cognitives qu'affectives. Les chercheurs s'inscrivant dans ce premier axe ont en commun de faire abondamment appel à la psychanalyse pour l'interprétation du comportement humain, aussi bien au niveau de la société globale (psychanalyse et société) qu'à celui des organisations économiques (psychanalyse et management).

Quant au second axe, il est principalement orienté vers l'analyse des conséquences pathologiques sur l'individu du travail et de son organisation. Ces conséquences sont de différentes formes: accidents de travail; maladies professionnelles; stress et épuisement professionnel; violences, meurtres et suicides d'origine professionnelle. Le discours dominant ici peut se résumer ainsi: l'individu qui trouve du plaisir dans le travail (acquisition des ressources financières, identification à un groupe, réalisation de soi, etc.) éprouve également de la souffrance procurée par ce même travail (nuisances diverses liées à l'organisation technique du travail, rapports hiérarchiques anxiogènes, âpreté de la compétition interpersonnelle, etc.). Cette vision ambivalente du travail a suscité beaucoup d'intérêt chez plusieurs chercheurs qui ont abondamment contribué à son élaboration et à son développement. On citera, entre autres, H. Selye (1975) très connu en Amérique du Nord pour ses travaux sur le stress et C. Dejours $(1987,1988)$ qui a beaucoup marqué l'évolution en France des études sur la psychopathologie professionnelle.

De manière générale, il ne fait aucun doute que l'analyse psychodynamique est d'un apport capital pour l'exploration de ce qu'on peut considérer comme les "zones d'ombre » du comportement humain, ainsi que pour la compréhension des mécanismes de production des pathologies professionnelles subies par l'individu. L'originalité de cette démarche réside principalement dans l'importance qui est accordée aux problèmes d'individualisation, d'intériorisation et de subjectivation du phénomène organisationnel. Ce dernier ne peut être appréhendé indépendamment des 
expériences personnelles et subjectives des individus présents dans l'organisation. C'est sans doute cela la principale faiblesse de cette démarche qui voit dans l'individu organisationnel un sujet à la fois prisonnier de ses pulsions et de ses désirs, et victime passive des contraintes organisationnelles. Or l'analyse stratégique nous a bien montré combien l'individu, agissant comme acteur, participe entièrement au jeu organisationnel en l'infléchissant dans un sens plus proactif.

La revue des perspectives et des courants ayant marqué l'analyse des organisations permet maintenant de s'interroger sur l'importance et la pertinence de ce champ de recherches en Afrique. C'est à cela que va être consacrée la partie suivante.

\section{Une Production Africaine Emergente et Prometteuse}

L'analyse des organisations, telle que nous venons d'en donner un aperçu, a connu un développement tardif en Afrique. Des études ont bien été réalisées, ici et là, pour tenter de comprendre le fonctionnement des sociétés africaines à partir des théories d'organisation existantes (P. Blunt, 1983; M. N. Kiggundu, J. J. Jorgensen, et T. Hafsi, 1983; M. N. Kiggundu, 1986). Certains travaux ont même conduit à l'élaboration de paradigmes susceptibles de rendre compte de la réalité organisationnelle africaine. C'est ainsi par exemple qu'un des paradigmes les plus utilisés, en sciences politiques et sociales, a été proposé par J.-F. Bayart (1989) dans sa tentative de théorisation du phénomène, très répandu en Afrique, d'accumulation redistributive. Nous dirons quelques mots, plus loin, de ce paradigme fort connu sous le nom de politique du ventre. Cependant, et comparativement à la situation des pays occidentaux, latino-américains ou asiatiques, le champ organisationnel africain reste insuffisamment exploré quoique très fécond. Avant de chercher à comprendre les raisons de cette situation, il convient au préalable de dégager quelques principales orientations thématiques de la production africaine actuelle sur les organisations $^{14}$.

\section{Regard sur la production africaine}

Parmi les différentes perspectives d'analyse des organisations répertoriées ci-dessus, deux semblent privilégiées dans la production africaine actuelle ${ }^{15}:$ la perspective rationaliste et fonctionnaliste d'une part, et la perspective humaniste et culturaliste $d$ 'autre part. $A$ la première on peut rattacher quelques réflexions développées par différents auteurs sur la genèse et le fonctionnement du phénomène bureaucratique en Afrique. Quant à la seconde, elle regroupe différents travaux sur les possibilités d'émergence de modèles africains de management et de développement. Il est très important de mentionner que quelque soit la perspective d'analyse considérée, la question 
centrale débattue est celle du rapport entre l'environnement socioculturel africain et le fonctionnement des organisations.

\section{L'analyse sociopolitique du phénomène bureaucratique}

Le mouvement de colonisation, qui a été déterminant dans le changement des sociétés traditionnelles africaines, a provoqué une profonde refonte de ces dernières. Elles sont progressivement devenues, avec plus ou moins de bonheur, des sociétés d'organisation au sens d'A. Etzioni (1971). Sous l'influence déterminante de la dynamique coloniale et postcoloniale, le modèle d'organisation de la bureaucratie administrative s'est rapidement imposé aux dépens de celui de la tradition principalement incarné par les chefferies traditionnelles dont certaines (à l'instar du sultanat bamoun au Cameroun) sont le lieu de concentration de l'autorité politique traditionnelle et de l'autorité religieuse. Cela est loin d'être surprenant dans la mesure où la dynamique coloniale (conformément à la vision wébérienne de la rationalisation des institutions) a principalement consisté à développer sur place, en Afrique, des structures étatiques supposées plus fonctionnelles et plus performantes par rapport aux structures traditionnelles anciennes. C'est du reste sur la base de ces structures étatiques nouvelles que s'est construite la nouvelle société africaine. Au fil du temps, il s'est établi une très forte analogie entre l'organisation et l'administration étatique davantage perçue comme une source de pesanteurs diverses et un lieu de corruption généralisée. Il ne fait aucun doute que l'analyse des organisations africaines a été longuement et fortement marquée par ce préjugé défavorable sur le fonctionnement de l'administration publique.

Différents travaux (historiques, sociologiques et politiques), sur l'émergence et le fonctionnement des bureaucraties africaines, ont permis d'en savoir davantage sur cette question préoccupante. Le cheminement historique des sociétés traditionnelles (notamment africaines) vers la bureaucratie administrative a été étudié, entre autres, par S. N. Eisenstadt (1973) et C. Coquery-Vidrovitch (1983). L'analyse du pouvoir comme enjeu principal du fonctionnement des bureaucraties africaines contemporaines a également été faite par différents auteurs (J.-F. Médard, 1983; G. Conac, 1983; D. Bigo, 1993) ${ }^{16}$. On doit à R. Price (1975), A. Schwarz (1983), J.-C. Gautron (1983), D. Brown (1989), D. R. Bognon (1990) et J.-F. Médard (1992) d'intéressantes descriptions sur les formes de représentation de la bureaucratie et sur les dysfonctions au sein de l'administration bureaucratique en Afrique.

A. Schwarz (1983), partant de l'exemple zaïrois (actuellement République Démocratique du Congo), montre ainsi comment l'expression du rapport à la modernité occidentale s'opère par une intériorisation abusive des comportements bureaucratiques à travers, par exemple, la tenue vestimentaire et des formes d'expressions langagières. De tels comportements, qui suscitent parfois un préjugé défavorable en Occident même, sont plutôt valorisés dans le contexte de ce pays parce que conférant une position de domination dans la 
société. Quant à D. Brown (1989), il se réfère particulièrement à la situation libérienne pour constater qu'ici le fonctionnement de la bureaucratie administrative obéit à une finalité totalement différente de celle énoncée par $\mathrm{M}$. Weber, à savoir la rationalisation en vue d'une plus grande efficacité organisationnelle. La finalité prédominante dans le cas étudié est la recherche de la stabilité et le renforcement du lien social au sein d'une catégorie sociale élitiste. Ainsi explique-t-il la forte bureaucratisation des structures administratives publiques au Libéria, jusqu'au coup d'Etat militaire de 1980 suivi de l'éclatement de la guerre civile quelques années plus tard, par le souci d'une plus grande cohésion interne du système politico-administratif longtemps entretenu par les élites dirigeantes (Libériens d'origine américaine, descendants d'esclaves retournés en Afrique) aux dépens du reste de la population (Libériens du terroir communément appelés les Natives).

Enfin, d'autres auteurs ont fait une analyse politique profonde, et très critique, des administrations bureaucratiques africaines qu'ils rendent en grande partie responsables du retard économique de l'A frique (O. Aktouf, 1989b; J.-F. Bayart, 1989, 1997). Une précision sur J.-F. Bayart (1989) pour dire qu'il s'est beaucoup penché sur le fonctionnement de l'Etat postcolonial en Afrique, modèle plus ou moins réussi de l'Etat bureaucratique dans les pays coloniaux d'Europe, pour montrer la place dominante des pratiques d'accumulation redistributive des ressources aux dépens de celles d'accumulation productive. De telles pratiques sont symbolisées par l'usage très répandu de métaphores relatives à la consommation alimentaire, mais dont les significations multiples vont bien au-delà de ce type de consommation (ventre, manger, mangeoire, etc.).

Tous ces travaux se sont développés autour d'un même fil conducteur. Au lieu d'être ce qu'on a voulu qu'elle devienne (un système opérationnel et performant), l'organisation bureaucratique africaine à l'instar de celles de l'Occident est devenue un système dysfonctionnel, générateur de contre-performances économiques et peu susceptible de contribuer au développement personnel des individus. Naturellement, tout ceci n'est pas sans rapport avec la crise politico-institutionnelle récurrente dans les sociétés africaines actuelles. Le mouvement grandissant de privatisation des entreprises et des services publics, particulièrement intense en Afrique, est bien une des conséquences de ce constat notoire ; même si on peut s'interroger sur les non-dits, les enjeux véritables et les résultats effectifs de ces privatisations (A. Henry, 1993; E. Kamdem, 1996d). A l'évidence, cet échec de l'organisation bureaucratique africaine dans son mode de fonctionnement est un élément d'explication de la désaffection des populations pour l'analyse des dynamiques sociales au sein des ensembles organisés. Si l'attitude du public peut être compréhensible, celle des chercheurs africains (peu engagés dans ce genre d'études) l'est moins. On reviendra plus loin sur cette question. 


\section{$L$ 'analyse interculturelle du management et du développement}

Ce thème est un des principaux pôles d'intérêt actuels des recherches sur le changement en Afrique. Les succès économiques éclatants observés ces dernières années au Japon et chez les autres « dragons industriels » asiatiques (Corée du Sud, Hong Kong, Singapour, Taïwan), comparés aux nombreux et piteux échecs économiques rencontrés dans la majorité des pays africains, ont suscité un regain d'intérêt pour l'étude approfondie des causes des échecs et des conditions de réussite économique en Afrique. A cela est venue s'ajouter, depuis le début des années quatre-vingt, la nouvelle donne économique et politique mondiale sur la mondialisation des marchés. C'est dans ce contexte général que l'analyse des organisations, en Afrique, a pris un tournant nouveau pour ne plus se limiter au seul champ de la remise en cause de l'administration bureaucratique. Le champ émergent, de plus en plus prisé par les chercheurs (principalement philosophes, sociologues, anthropologues et socio-économistes, gestionnaires et spécialistes des sciences de gestion) est celui du management des organisations, dans la perspective du développement à la fois économique et social. Pratiquement tous les chercheurs intéressés par ces questions mettent l'accent sur le paradoxe des traditions locales et nationales africaines: dans quelles mesures peuvent-elles ou ne peuvent-elles pas être prises en compte dans les stratégies de management et de développement? En somme, ce paradoxe invite à une réflexion beaucoup plus globale sur la question délicate de l'enracinement et de l'ouverture des organisations et des sociétés africaines. Dans une telle démarche, la culture a souvent été considérée comme une variable externe, à savoir un élément central d'intermédiation entre les différents modèles de management à travers le monde. S'agissant principalement de la place et de l'importance des cultures africaines dans le fonctionnement des organisations, trois tendances majeures émergent actuellement des travaux sur la question: une première tendance beaucoup plus critique et radicalement hostile au discours sur les cultures africaines, une seconde tout aussi critique mais qui invite surtout au renouvellement du discours sur la dimension culturelle du développement, et enfin une troisième, résolument optimiste, qui s'interroge sur les possibilités et les modalités d'un enracinement plus fructueux des pratiques de management dans les sociétés africaines.

Les ténors du courant critique radical voient dans les cultures africaines l'une des principales causes du retard économique du continent, parce qu'elles sont loin d'épouser les normes reconnues comme dominantes dans les sociétés économiquement développées (compétition individuelle, accumulation matérielle, calcul économique, rentabilité financière, etc.). Ils considèrent que l'attachement des populations à leurs traditions culturelles est susceptible de limiter leurs capacités d'adaptation à la compétition économique internationale. Dans cette hypothèse, la réussite économique suppose une certaine distanciation à l'égard de ces traditions qu'il convient de considérer 
plus comme une affaire du passé. Cette vision du rapport entre les cultures africaines, le management et le développement est très présente chez G. Hyden (1983) qui a développé le concept d'économie d'affection ${ }^{17}$ pour montrer la rupture entre le capitalisme occidental, plus productiviste et plus rentabiliste, et l'organisation économique des sociétés africaines rurales dont on observe un très fort enracinement traditionnel. Il voit justement dans cet enracinement l'obstacle majeur au changement social et au développement économique de ces sociétés. D. Etounga-Manguellé (1990) partage le même discours en s'interrogeant sur la nécessité d'un ajustement culture ${ }^{18}$ en Afrique. Cette idée se retrouve aussi fortement exprimée par A. Kabou (1991) qui s'interroge à son tour sur le refus ${ }^{19}$ du développement par l'Afrique tant qu'elle demeure largement dépendante de la force attractive des traditions.

Le second courant se veut plus réformiste et cherche à dépasser la vision culturaliste du développement ${ }^{20}$. Il voudrait davantage élucider la confusion qui entoure le discours sur la culture et le développement. Il prône également un renouvellement des analyses sur le thème de la culture pour que ce dernier soit abordé dans une perspective résolument constructiviste (la culture non comme une réalité fixe et immuable, mais plus dynamique et changeante). Cette vision réformiste de la culture est développée par différents auteurs. On la retrouve dans les analyses de P. E. A. Elungu (1987) qui montre bien la distance entre la tradition africaine et la rationalité moderne; distance qui explique l'impasse dans laquelle se trouvent les sociétés africaines actuelles. Pour sa part, D. Desjeux (1991) inscrit la question de la culture et du développement dans une démarche stratégique. Cette dernière permet de voir comment les différents acteurs (institutionnels et individuels) impliqués dans des projets de développement élaborent des stratégies pour orienter ou contrôler ces projets. C'est à partir de la connaissance que ces acteurs ont de l'organisation et du fonctionnement de leur société qu'ils arrivent à se doter des ressources nécessaires à la réalisation de leurs objectifs. Avec M. Poncelet (1994), on assiste à un inventaire et à une relecture critique des principaux discours sur la dimension culturelle du développement. Son analyse apporte un éclairage nouveau sur la portée et les limites de ces discours, en même temps qu'elle constitue une base de reformulation des politiques de développement en Afrique et ailleurs dans le monde. Cette dernière préoccupation est de plus en plus présente dans les orientations stratégiques des institutions financières internationales, notamment la Banque mondiale dont on sait par ailleurs qu'elle a longtemps privilégié les dimensions économiques et financières du développement (I. Serageldin et J. Taboroff, 1994). Sur un autre plan, il est important de relever l'analyse critique que fait J. Roitman (1995) de quelques travaux récents visant à remettre en cause l'universalité du capitalisme occidental pour s'intéresser davantage à quelques expériences, à travers le monde et notamment en Afrique, de ce qu'elle perçoit comme étant des modèles de capitalisme culturel $^{21}$. Ces différents travaux qui, selon l'auteur, occultent 
quelque peu les conditions historiques du développement du capitalisme occidental, invitent considérablement à une définition de la culture en tant que sphère autonome, et donc potentiellement déterminante... dans l'émergence de ces différentes formes de capitalisme en dehors de l'Occident. On peut enfin signaler l'analyse critique que J.-F. Bayart (1996) fait du concept de culture dont il se demande d'ailleurs s'il ne s'agit pas d'un mot à jeter (J.-F. Bayart, 1996, p. 69). Vraisemblablement faite sous l'influence des conflits politiques grandissants en Afrique et dans le monde, autour des questions identitaires, cette analyse permet de mieux comprendre les représentations culturelles qui sont à la source de ces conflits ainsi que les raisons culturelles de l'action politique qui, selon lui, participent au premier chef de l'imaginaire (J.-F. Bayart, 1996, p. 125). Au fond, on peut résumer ce courant réformiste en disant qu'il aborde bien la question de la culture tout en laissant entièrement ouvert le débat sur le rôle de la culture dans le fonctionnement de l'organisation africaine.

Quant au troisième courant, on peut le qualifier de managérial ou encore d'entrepreneurial en ce sens qu'il est principalement incarné par des chercheurs qui, sans nécessairement être issus d'institutions de formation en gestion, s'intéressent à l'analyse des dynamiques sociales dans les entreprises africaines ainsi qu'à la recherche de paradigmes susceptibles de rendre compte de ces dynamiques. Pour ces chercheurs, les traditions africaines sont une variable déterminante du fonctionnement des organisations modernes. Il convient donc de se pencher davantage sur ces traditions pour voir comment elles peuvent se manifester positivement ou négativement dans le management des entreprises et des organisations africaines.

Cette préoccupation centrale est abordée suivant des thématiques différentes et variées. De nombreuses études ont déjà été réalisées sur les conditions historiques du développement de l'entreprise en Afrique (Collectif, 1983). H. Bourgoin (1984) a été l'un des premiers à engager une réflexion systématique sur l'entreprise africaine et les modalités de son management. Les trajectoires et les profils d'entrepreneurs sont étudiés par J. Chevassu et A. Vallette (1975), ainsi que par C. Miras (1981) et Y.-A. Fauré (1994) en Côte-d'Ivoire ; P. Kennedy (1980) au Ghana; P. Labazée (1988) au Burkina Faso; P.-N. Denieuil (1992) en Tunisie; J.-F. Médard (1992). D’autres auteurs se sont davantage intéressés aux pratiques des gestionnaires et des dirigeants, ainsi qu'aux comportements des travailleurs pour essayer de comprendre leurs fondements et leurs logiques: O. Aktouf (1986) en Algérie; Ph. d'Iribarne (1986) au Cameroun; G. Desauney (1987) en Côte-d'Ivoire; G. Grégoire et P. Labazée (1993) en Afrique de l'Ouest; Th. Dzaka et M. Milandou (1994) au Congo; E. Kamdem (1996b) au Cameroun; M. Zadi Kessy (1998) en Côte-d'Ivoire. Pour sa part, E. Grégoire (1986) analyse le cheminement historique des commerçants du Niger. Quant à J.-P. Warnier (1993), il se penche sur la situation camerounaise pour étudier les dimensions historique, 
géographique, sociologique, politique, économique et même psychanalytique du succès de quelques entrepreneurs dans ce pays. Le rapport entre l'organisation sociale traditionnelle, l'accumulation et le développement de l'entreprise est étudié dans différents pays : Nigeria (S. Berry, 1985); Ghana (P. Kennedy, 1988); Maroc (H. Zaoual, 1990); Cameroun (E. Kamdem, 1999; P. Geschiere et P. Konings, 1993); Tunisie(R.Zghal, 1994); Algérie (D. Mercure, 1997). Des réflexions abondantes et enrichissantes sur les possibilités et les difficultés de développement de l'entreprise et de modèles de management en Afrique sont engagées, entre autres, par Ph. Delalande (1987); J. Mac Gaffey (1987); G. Hénault et R. M'Rabet (1990); A. Henry (1991); P. Blunt et M. L. Jones (1992); P. Kammogne Fokam (1993); P. Blunt, M. L. Jones et D. Richards $(1993)^{22}$; Y. Gasse et C. Carrier (1994) ${ }^{23}$; S. Ellis et Y.-A. Fauré (1995); E. Kamdem (1996a); E.-M. Hernandez (1998). Dans ce dernier registre, il convient de relever tout particulièrement la récente production collective d'un groupe de chercheurs internationaux, dans l'ouvrage Organisations économiques et cultures africaines: de l'homo oeconomicus et l'homo situs (1996).

Comme on peut le constater à travers les travaux recensés ci-dessus, l'organisation africaine et principalement l'entreprise est devenue un champ de recherche particulièrement fécond depuis le début des années quatre-vingt. Rappelons encore une fois que le fil conducteur de ces différentes recherches est l'étude des articulations entre la tradition africaine et la modernité occidentale, dans le cadre des organisations de production économique. On peut risquer l'affirmation qu'il s'agit là de l'axe dominant actuel de l'analyse des organisations en Afrique. Voyons maintenant quelques-uns des problèmes posés par le développement de la recherche sur les organisations en Afrique.

\section{L'organisation: un objet d'étude encore peu et mal connu}

La multiplication et la diversification de la production africaine sur les organisations, tel qu'on vient d'en avoir un aperçu ci-dessus, ne doivent pas faire illusion. L'organisation, comme objet d'étude, est encore peu et mal connue en Afrique; surtout si l'on compare la production africaine à celle déjà effectuée dans différentes régions du monde. 11 me semble qu'on peut identifier les raisons de cette situation à deux niveaux principalement: la représentation négative de l'organisation et la conceptualisation même de l'objet d'étude. Je m'expliquerai également sur la légèreté et la relativité de l'argumentation matérielle et financière très souvent avancée, ici et là, pour expliquer l'insuffisance de la production scientifique des chercheurs africains, principalement dans le domaine des sciences sociales et de la sociologie des organisations. 


\section{Le contexte du développement et la représentation négative de l'organisation}

L'organisation, en tant qu'objet d'étude, pose problème dans les milieux universitaires africains. Il est utile de rappeler que le développement de l'analyse des organisations, en Occident, a connu deux faits historiques majeurs: la place centrale de l'organisation productive et l'influence déterminante des théories sociologiques de l'organisation. Comme il a déjà été signalé plus haut, l'intérêt pour la compréhension des dynamiques sociales en termes d'organisation est né au début du siècle dernier, à la faveur de la prolifération des structures de production économique et de l'extension du mouvement de rationalisation en Occident. C'est d'abord à partir d'une profonde imprégnation des réalités des milieux industriels que les pionniers que sont $\mathrm{F}$. W. Taylor et $\mathrm{H}$. Fayol ont posé les jalons de ce qui, après plusieurs détours, est devenu aujourd'hui l'analyse des organisations. On ne le dira jamais assez, la finalité première de toute cette démarche se résume en une phrase: plus de rationalisation pour plus de rentabilisation. A la faveur du mouvement de colonisation, 1'Afrique a connu la pénétration en force des modèles d'organisation et de production économique importés d'Occident. Le choc culturel né de la rencontre de ces deux visions du monde (celle de l'Afrique plus relationnelle et plus existentielle d'une part, et celle de l'Occident plus rationaliste et plus rentabiliste d'autre part) a considérablement ébranlé les consciences. C'est un peu cela que veut exprimer le philosophe congolais P. E. A. Elungu (1987) quand il souligne la rupture manifeste entre la tradition africaine et la rationalité moderne $\mathrm{e}^{24}$. C'est ainsi que l'organisation (et principalement l'organisation de production économique), loin de susciter un attrait aux yeux des Africains, est plutôt devenue une source de méfiance; car étant susceptible de produire toutes sortes de nuisances chez l'individu. C'est de cette manière qu'on peut comprendre le désintérêt voire l'aversion de beaucoup d'Africains pour l'organisation ainsi représentée dans leur imaginaire collectif ${ }^{25}$. Le travail du Blanc ne finit jamais, telle est la phrase quasi rituelle prononcée encore aujourd'hui par nombre d'Africains (même très familiers des cultures occidentales) chaque fois qu'ils veulent exprimer la lassitude et la désaffection ressenties à la fois dans le travail industriel et dans son mode d'organisation. L'organisation comme lieu de travail est davantage perçue comme cadre de production de la souffrance, pour paraphraser C. Dejours $(1987,1988)^{26}$.

\section{La faible conceptualisation de l'objet d'étude}

Très souvent en Afrique, le concept d'organisation est largement confondu avec celui d'organisation administrative ou politique. Cela peut être analysé comme une des conséquences de la dérive bureaucratique constatée dans le fonctionnement des sociétés africaines actuelles. L'administration publique est longtemps demeurée (et demeure encore) un modèle d'organisation dominant 
et dominateur, par rapport à d'autres formes d'organisation existantes (traditionnelles, associatives, corporatistes, etc.) qui, dans bien des cas, sont largement assujetties à la première. C'est probablement pourquoi les chercheurs africains en sociologie et en sciences sociales ne se sont pas beaucoup passionnés pour cet objet d'étude davantage considéré comme une préoccupation des chercheurs en sciences juridiques et politiques. Une illustration intéressante de ce malentendu sur le concept d'organisation. Lors des interventions menées dans différentes entreprises africaines, $j$ 'ai souvent été vivement interpellé afin de justifier l'utilisation du concept d'organisation pour désigner des entreprises (industrielles, commerciales ou de service). Sans mettre en cause la bonne foi de mes interlocuteurs, il me semble que ces interpellations sont révélatrices d'une confusion certaine quand au sens et au contenu du concept d'organisation. Cet exemple est riche d'enseignements, du point de vue du contexte de développement de la recherche sur l'analyse des organisations en Afrique. Il y a sûrement un important effort pédagogique à faire pour mieux élucider le concept d'organisation et montrer l'importance des phénomènes organisationnels dans la vie en société.

\section{La relativité de l'argumentation financière}

De manière générale, la production scientifique africaine dans bien des domaines de recherche est limitée par rapport à l'immensité des problèmes à étudier. Cela est aussi vrai pour l'analyse des organisations. On entend très souvent, ici et là, invoquer l'insuffisance voire l'absence des ressources financières et matérielles nécessaires au développement de la recherche en général. Il est très important de souligner qu'il s'agit là d'une argumentation juste mais insuffisante. Il est exact qu'on assiste, depuis quelques années, à une déliquescence inquiétante des institutions nationales africaines de recherche. Ces dernières, longtemps et quasi exclusivement subventionnées par les pouvoirs publics, n'arrivent à survivre que très difficilement en l'absence de ressources nécessaires. Les nombreuses crises économiques, politiques et institutionnelles dans plusieurs Etats n'ont pas permis à ces derniers de contribuer efficacement au développement de la recherche. C'est pourquoi cette activité se trouve essentiellement extravertie aujourd'hui. Les rares recherches actuellement entreprises un peu partout en Afrique le sont majoritairement ou exclusivement avec des financements extérieurs. Ce constat ne doit pas faire perdre de vue que le problème central est moins celui des sources de financement. Il faut certainement une affirmation de la volonté profonde et manifeste des parties concernées (pouvoirs publics, institutions universitaires, partenaires privés, formateurs professionnels, chercheurs scientifiques) de vraiment considérer la recherche et la diffusion des résultats de recherche comme des activités susceptibles de contribuer grandement au développement intégral de la société. En somme, on peut risquer l'affirmation que le développement de la recherche en Afrique aujourd'hui (y compris dans 
le domaine des organisations) est d'abord une affaire de volonté politique des dirigeants et d'engagement personnel des chercheurs avant d'être une affaire de disponibilité des ressources financières ${ }^{27}$.

\section{Conclusion}

L'entreprise apparaît sans aucun doute comme le champ privilégié actuel de l'analyse des organisations en Afrique. Si l'on considère tout ce qui est écrit et produit en ce moment sur l'Afrique dans différents champs disciplinaires, il apparaît bien à l'évidence que l'entreprise, sa genèse, son organisation, son fonctionnement, sa place dans la société, occupent une position centrale. On peut faire un rapprochement avec d'autres contextes pour voir qu'en Occident, les premières études formelles et systématiques sur les organisations sont issues des milieux industriels. On ne doit pas voir dans la situation africaine présente une simple réaction mimétique des chercheurs intéressés par les dynamiques sociales. C'est vraisemblablement une indication très significative du rôle de plus en plus important que l'entreprise, l'entrepreneur et le gestionnaire sont appelés à jouer dans l'édification de la nouvelle société africaine en construction. Société d'organisation, de compétition, de production, d'accumulation, d'abondance et de bien-être matériel. Mais aussi et paradoxalement société de marginalisation, d'exclusion, de crise éthique et identitaire.

\section{Notes}

Ce texte a fait l'objet d'une communication au 14ème Congrès Mondial de Sociologie, organisé par l'Association Internationale de Sociologie (AIS), à Montréal, Canada, du 26 juillet au 01 août 1998.

1. Il n'est donc pas surprenant qu'à l'aube de la grande crise socio-économique que traverse l'Afrique depuis le début des années quatre-vingt, les institutions nationales de recherche en sciences sociales aient été fermées dans la plus part des pays, notamment au Cameroun où l'Institut des Sciences Humaines (ISH) a cessé de fonctionner en 1993.

2. Voir F. W. Taylor, La direction scientifique des entreprises. Paris, Dunod, 1957, pp. 68-81. Première édition en anglais en 1911.

3. Il s'agit du Groupe industriel Commanbault, alors spécialisé dans l'exploitation des mines de fer dans la région de Saint-Etienne, en France.

4. H. Fayol souligne que le fonctionnement de toute organisation s'opère à travers six catégories d'opérations (techniques, commerciales, financières, de sécurité, de comptabilié et d'administration). A ses yeux, c'est bien cette dernière longtemps occultée qu'il convient de revaloriser davantage.

5. On peut citer à titre d'illustration ce qu'on a appelé la « Guerre froide » et qui a opposé, au début des années soixante, les pays du bloc capitaliste conduits par les Etats-Unis et ceux du bloc socialiste conduits par l'ex-URSS. Un des enjeux de cette guerre était bien le positionnement idéologique et économique de ces 
différents pays, dans une perspective de contrôle du reste du monde. Les processus de prise de décision ont été rudement mis à l'épreuve lors du conflit des missiles soviétiques installés à Cuba, à quelques kilomètres du territoire américain. On le sait bien, le monde a été à deux doigts d'une guerre nucléaire, n'eut été la décision des dirigeants soviétiques de retirer les missiles en question.

6. Les mots en gras sont soulignés par l'auteur de la citation.

7. Chacun de ces trois rôles principaux regroupe une série de rôles secondaires. Les rôles interpersonnels regroupent les rôles de symbole, de leader, d'agent de liaison. Quant aux rôles informationnels, on y retrouve les rôles d'observateur, de diffuseur, de porte-parole. Enfin les rôles décisionnels sont répartis en rôles d'entrepreneur, de régulateur, de répartiteur de ressources, de négociateur.

8. Nous évoquerons ces expériences plus loin dans la rubrique consacrée à la perspective humaniste et culturaliste.

9. E. Mayo $(1933,1945)$.

10. K. Lewin $(1935,1947,1958)$. Voir aussi J. A. C. Brown (1954) et G. Friedmann (1947) qui ont, à des degrés divers, porté une attention soutenue à l'étude des problèmes humains dans l'industrie.

11. Le développement et le succès, dans pratiquement toutes les Ecoles de gestion à travers le monde, des cours de Comportement dans l'organisation, de Psychosociologie des organisations, ou encore de Dynamique des relations humaines, est bien un indicateur incontestable de la place centrale de l'humain et du social dans l'enseignement et la pratique de la gestion.

12. On trouve chez L. Smircich et M. B. Calas (1987, pp. 235-239) une clarification des deux qualificatifs (externe et interne) appliqués à la culture.

13. C'est bien la raison pour laquelle ces deux courants sont rangés dans la même perspective humaniste et culturaliste.

14. Cette formulation ne manquera pas de susciter quelques critiques, tout à fait fondées, sur la délimitation de l'étendue de l'espace africain dont il est question ici. En réalité, il s'agit beaucoup plus de l'espace francophone et dans une moindre mesure de l'espace anglophone au sud du Sahara. Nous reconnaissons bien les limites de ce choix qui ne rend pas compte de la production scientifique (effective ou supposée) sur les organisations dans d'autres espaces linguistiques africains (arabophone, hispanophone, lusophone).

15. Il s'agit de la production faite aussi bien par les chercheurs africains (du terroir et de la diaspora) que par des chercheurs originaires d'autres régions du monde, principalement de l'Europe occidentale (France, Grande-Bretagne) et de l'Amérique du nord (Canada, Etats-Unis).

16. La revue Pouvoirs, ${ }^{\circ} 25,1983$ consacre un abondant et enrichissant dossier sur l'analyse du pouvoir dans les bureaucraties africaines postcoloniales.

17. Hyden, G., No Shortcuts to Progress : African Development Management in Perspective. London, Heinemann, 1983.

18. Etounga-Manguellé, D., L'Afrique a-t-elle besoin d'un programme d'ajustement culturel? Yvry-sur-Seine, Editions Nouvelle du Sud, 1990.

19. Kabou, A., Et si l'Afrique refusait le développement? Paris, L'Harmattan, 1991. 
20. Dans ce courant, nous faisons mention de travaux (M. Poncelet, 1994; J.-F. Bayart, 1996) qu'on ne devrait que partiellement ranger dans la production africaine sur l'analyse de la culture. En effet, ces travaux qui ne sont pas exclusivement consacrés à l'Afrique contiennnent d'importantes et intéressantes analyses de situations africaines. C'est bien la raison pour laquelle nous en parlons ici.

21. L'intérêt grandissant des travaux sur les cultures africaines et l'entreprise ne manque d'ailleurs pas de soulever quelques problèmes sur la pertinence de ce genre de travaux. On trouve chez J. Roitman (1995) une critique très approfondie de quelques travaux récents sur la question, en particulier ceux de J.-P. Warnier (1993), P. Geschiere et P. Konigs (1993) et J.-F. Bayart, (1994).

22. La contribution de ces trois auteurs est extrêmement entichissante, du point de vue didactique. Leur ouvrage présente une collection de textes, de cas et d'exercices sur plusieurs domaines du management en Afrique (environnement social, stratégie et direction, cadre du travail, changement et conflit.

23. La même remarque précédente est aussi valable pour ces deux auteurs et pour les mêmes raisons.

24. Elungu, P. E. A. Tradition africaine et rationalité moderne. Paris, L'Harmattan, 1987.

25. Une telle représentation de l'organisation n'est pas propre aux Africains. On peut en juger par l'abondance des analyses mettant en évidence les méfaits de la vie organisationnelle sur les individus, en Occident et en Asie. Cela a d'ailleurs été souligné, plus haut, dans l'évocation des formes de psychopathologie professionnelle en Occident.

26. Dejours, C., (dir.), Plaisir et souffrance dans le travail, 2 tomes. Paris, CNRS, 1987 et 1988.

27. Il est important de souligner ici le rôle central et fort utile de certaines structures de financement et vulgarisation de la recherche, à l'instar du Conseil Africain pour le Développement de la Recherche en Sciences Sociales en Afrique (CODESRIA).

\section{Bibliographie}

Aktouf, O., Le travail industriel contre l'homme? Alger, Entreprise Nationale du Livre, Office des Publications Universitaires, 1986.

Aktouf, O., Le management entre tradition et renouvellement. Montréal, Gaëtan Morin, 1989a.

Aktouf, O., Algérie, entre l'exil et la curée. Paris, L'Harmattan, 1989b.

Aktouf, O., " Le symbolisme et la culture d'entreprise : des abus conceptuels aux réalités du terrain », Chanlat, J.-F. (dir), L 'individu dans l'organisation: les dimensions oubliées. Québec, Les Presses de l'Université Laval; Paris, Editions Eska, 1990, pp. 553-588.

Anzieu, D., Le groupe et l'inconscient. L'imaginaire groupal. Paris, Dunod, 1975.

Aubert, N., Enriquez, E. et de Gaulejac, V., (dir.), Le sexe du pouvoir: femmes, hommes et pouvoirs dans les organisations. Paris, Epi, 1986.

Bayart, J.-F., L'Etat en Afrique: la politique du ventre. Paris, Fayard, 1989.

Bayart, J.-F., (dir.), La réinvention du capitalisme. Paris, Karthala, 1994. 
Bayart, J.-F., L'illusion identitaire. Paris, 1996.

Bayart, J.-F., Stephen, E. et Hibou, B., La criminalisation de l'Etat en Afrique. Paris, Editions Complexe, 1997.

Bernoux, Ph., Sociologie des organisations. Paris, Seuil, 1985.

Berry, S., Fathers work for their sons. Accumulation, Mobility and Class Formation in an Extended Yoruba Community. Berkeley, University of California Press, 1985.

Bertalanffy, L., (von), Théorie générale des systèmes : physique, biologie, psychologie, sociologie, philosophie. Paris, Dunod, 1973. Première édition en anglais en 1968.

Bertrand, Y., Culture organisationnelle. Québec, Presses de l'Université du Québec, 1991.

Bigo, D., Pouvoir et obéissance en Centrafrique. Paris, Karthala, 1993.

Blunt, P., Organizational Theory and Behavior: An African Perspective. Longman, London, 1983.

Blunt, P., et Jones, M. L., Managing Organisations in Africa. Berlin and New York, Walter de Gruyter, 1992.

Blunt, P., Jones, M. L., and Richards, D., Managing Organisations in Africa: Readings, Cases and Exercises. Berlin and New York, Walter de Gruyter, 1993.

Bollinger, D., et Hofstede, G., Les diffërences culturelles dans le management: comment chaque pays gère-t-il ses hommes? Paris, Editions d'organisation, 1987.

Bognon, D. R., "Les services administratifs en Côte-d'Ivoire ». Gestion, Revue internationale de gestion, 15(1), février 1990, pp. 67-73.

Bosche, M., « Corporate Culture: la culture sans histoire ». Revue française de gestion, $\mathrm{n}^{\circ}$ 47-48, septembre-octobre 1984, pp. 29-39.

Bourgoin, H., L'Afrique malade du management. Paris, Editions Jean Picollec, 1984.

Braverman, H., Travail et capitalisme monopoliste. Paris, Maspéro, 1976.

Brown, J. A. C., The Social Psychology of Industry: Human Relations in the Factory. London, Penguin Books, 1954.

Brown, D., " Bureaucracy as an issue in Third World Management: an African case study ». Public Administration and Development, 9, 1989, pp. 369-380.

Chanlat, J.-F., et Séguin, F., L'analyse des organisations : les composantes de l'organisation (tome 2). Montréal, Gaëtan Morin éditeur, 1987.

Chanlat, J.-F., « L'analyse des organisations, un regard sur la production anglo-saxonne contemporaine (1970-1988) ». Sociologie du travail, $\mathrm{n}^{\circ} 3, \mathrm{pp}$. $381-400,1989$.

Chanlat, J.-F., (dir), L'individu dans l'organisation: les dimensions oubliées. Québec, Les Presses de l'Université Laval; Paris, Editions Eska, 1990.

Chanlat, J.-F., « L'analyse des organisations, un regard sur la production de langue française contemporaine (1950-1990) ». Cahiers de recherche n $91-09$, Ecole des HEC de Montréal, 1991.

Chanlat, J.-F. Sciences sociales et management. Paris, Presses de l'Université Laval et Editions Eska, 1998. 
Chevassu, J., et Vallette, A., Les industriels de la Côte-d'Ivoire. Qui et pourquoi ? Abidjan, ORSTOM, 1975.

Collectif, Discours biologique et ordre social. Paris, Seuil, 1977.

Collectif, Entreprises et entrepreneurs en Afrique, 2 tomes. Paris, L'Harmattan, 1983.

Collectif, Organisations économiques et cultures africaines : de l'homo oeconomicus à l'homo situs. Paris et Montréal, L'Harmattan, 1996.

Conac, G., "Portrait du Chef d'Etat ». Revue Pouvoirs, n² 25, 1983, pp. 121-130.

Coquery-Vidrovitch, C., « A propos des racines historiques du pouvoir : 'chefferie' et 'tribalisme'». Revue Pouvoirs, n² 25, 1983, pp. 51-62.

Crozier, M., Le phénomène bureaucratique. Paris, Seuil, 1963.

Crozier, M., et Friedberg, E., L'acteur et le système. Paris, Seuil, 1977.

Deal, T. E., et Kennedy, A. A., Corporate Cultures. Reading, MA, Addison-Wesley, 1982.

Dejours, C., (dir.), Plaisir et souffrance dans le travail, 2 tomes. Paris, CNRS, 1987 et 1988.

Delalande, Ph., Gestion de l'entreprise industrielle en Afrique. Paris, Economica, 1987.

Denieuil, P.-N., Les entrepreneurs du développement. L'ethno-industrialisation en Tunisie: la dynamique de Sfax. Paris, L'Harmattan, 1992.

Desauney, G., « Les relations humaines dans les entreprises ivoiriennes ». Revue Française de Gestion, n ${ }^{\circ}$ 64, septembre-octobre 1987, pp. 95-101.

Desjeux, D., Le sens de l'autre. Stratégie, réseaux et culture en situation interculturelle. Paris, Unesco, 1991.

Dzaka, Th., et Milandou, M., «L'entrepreneuriat congolais à l'épreuve des pouvoirs magiques: une face cachée de la gestion culturelle du risque? ». Politique africaine, $\mathrm{n}^{\circ}$ 56, décembre 1994, pp. 108-118.

Eisenstadt, S. N., The Traditional Patrimonialism and Modern Neo-patrimonialism, Sage Research Paper. Beverly Hills and London, Sage, pub., inc., 1973.

Ellis, S., et Fauré, Y.-A., (dir.), Entreprises et entrepreneurs africains. Paris, Karthala / Orstom, 1995.

Elungu, P.E. A., Tradition africaine et rationalité moderne. Paris, L'Harmattan, 1987.

Enriquez, E., De la horde à l'Etat : essai de psychanalyse du lien social. Paris, Gallimard, 1983.

Etounga-Manguellé, D., L'Afrique a-t-elle besoin d'un programme d'ajustement culturel? Yvry-sur-Seine, Editions Nouvelles du Sud, 1990.

Etzioni, A., Les organisations modernes. Gembloux, Duculot, 1971.

Fauré, Y.-A., Petits entrepreneurs de Côte-d'lvoire: des professionnels en mal de développement. Paris, Karthala, 1994.

Fayol, H. Admistration idustrielle et générale. Paris, Dunod, 1970. Première édition en 1916.

Freud, S., Introduction à la psychanalyse. Paris, Payot, 1973.

Friedberg, E., L'analyse sociologique des organisations. Toulouse, Privat, 1971. 
Friedmann, G., Problemes humains du machinisme industriel. Paris, Gallimard, 1947.

Gasse, Y., et Carrier, C., Gestion de l'entreprise africaine. Dakar, Librairie ClairAfrique; Montréal, Les Presses de l'Université de Montréal, 1994.

Gautron, J.-C. « L'administration ». Revue Pouvoirs, n²5, 1983, pp. 107-120.

Geschiere, P., et Konings, P., (dir.) Itinéraires d'accumulation au Cameroun. Paris, Karthala, 1993.

Gouldner, A. W., Patterns of industrial bureaucracy. Glencoe, The Free Press, 1954.

Grégoire, E., Les Alhazai de Maradi: histoire d'un groupe de riches marchands sahéliens. Paris, Orstom, 1986.

Grégoire, E., et Labazée, P., (dir.) Grands commerçants d'Afrique de l'Ouest. Logiques et pratiques d'un groupe d'hommes d'affaires contemporains. Paris, Karthala / Orstom, 1993.

Hénault, G., et M'Rabet, R., L'entrepreneuriat en Afrique: culture, financement et développement. Paris, John Libbey Eurotext, 1990.

Hernandez, E.-M., Le management des entreprises africaines. Paris, L'Harmattan, 1998.

Henry, A., «Vers un modèle de management africain ». Cahiers d'Etudes Africaines, 124, XXXI-4, pp. 447-473, 1991.

Henry, A., «Les privatisations, une nouvelle 'sorcellerie' des Blancs? ». Afrique contemporaine, 165 , 1er trimestre 1993, pp. 10-18.

Hyden, G., No Shortcuts to Progress: African Development Management in Perspective. London, Heinemann, 1983.

Iribarne, Ph., (d'), «Cultures nationales et gestion: un problème de ponts roulants dans une usine camerounaise ». Annales des Mines-Gérer et Comprendre, décembre 1986, pp. 71-77.

Iribarne, Ph., (d'), La logique de l'honneur: gestion des entreprises et traditions nationales. Paris, Seuil, 1989.

Iribarne, $\mathrm{Ph} .,(\mathrm{d}$ '), «Contre l'anti-culturalisme primaire ». Revue française de gestion, novembre-décembre 1992, pp. 132-137.

Iribarne, Ph., (d')et coll., Cultures et mondialisation : gérer par-delà les frontières. Paris, Seuil, 1998.

Kabou, A., Et si l'Afrique refusait le développement? Paris, L'Harmattan, 1991.

Kamdem, E., «Réflexions autour du paradoxe africain : une perspective socio-anthropologique et managériale ». Gestion, vol. 24, n¹, 1999, pp. 57-67.

Kamdem, E., « Ni Taylor, ni folklore: pour un management interculturel et créatif ». Organizaçôes \& Sociedade, Revista da Escola de Administraçâo da UFBA, Brasil, vol. 3, n 6 , junho 1996a, pp. 97-126.

Kamdem, E., "Nouveau regard sur les pratiques de management au Cameroun », Collectif, Organisations économiques et cultures africaines: de l'homo oeconomicus à l'homo situs. Paris, L'Harmattan, 1996b, pp. 249-271.

Kamdem, E., Management et interculturalité en Afrique: expérience camerounaise. A paraître. 
Kamdem, E., «Privatisations et logiques sociales: enjeux complémentaires ou contradictoires? ». Communication au 15ème Congrès de l'Association Internationale des Sociologues de Langue Française (AISLF), Evora, Portugal, 8-12 juillet 1996d. A paraître.

Kammogne Fokam, P., L'entrepreneur africain face au défi d'exister. Paris, L'Harmattan, 1993.

Kast, E., et Rosenzweig, J. E. Contingency Views of Organization and Management. Chicago, Science Research Associates, 1973.

Kennedy, P., Ghanaian Businessmen. From Artisan to Capitalist Entrepreneur in a Dependent Economy. Munchen / London, Weltforum Verlag, 1980.

Kennedy, P., African Capitalism. The Struggle for Ascendency. Cambridge, Cambridge University Press, 1988.

Kets de Vries, M. F. R., et Miller, D., L'entreprise névrosée. Paris, McGraw-Hill, 1985.

Première édition en anglais en 1984.

Klein, M., Essais de psychanalyse. Paris, Payot, 1978.

Kiggundu, M. N., « Africa in Crisis: Can Organization Theory Help? ». Paper presented at the 45th Annual Meeting of the Academy of Management. San Diego, California, 11-14 August, 1986.

Kiggundu, M. N., Jorgensen, J. J. et Hafsi, T., « Administrative Theory and Practice in Developing Countries: A synthesis ». Administrative Science Quartely, vol. 28, $\mathrm{n}^{\circ}$ 1, pp. 66-84, 1983.

Kohut, H., Self psychology and the humanities: reflections on a new psychoanalytic approach. New York, Norton, 1985.

Labazée, P., Entreprises et entrepreneurs au Burkina Faso. Paris, Karthala, 1988.

Lapierre, L., «Intériorité, gestion et organisation: de la réalité psychique comme fondement de la gestion », Chanlat, J.-F., (dir), L'individu dans l'organisation : les dimensions oubliées. Québec, Les Presses de l'Université Laval ; Paris, Editions Eska, 1990, pp. 263-278.

Lapierre, L., Imaginaire et leadership, 3 tomes. Montréal, Québec-Amérique, 1992.

Lemaître, N., «La culture d'entreprise, facteur de performance ». Revue française de gestion, $\mathrm{n}^{\circ}$ 47-48, septembre-octobre 1984, pp. 153-161.

Levy-Leboyer, C., Psychologie des organisations. Paris, Presses Universitaires de France, 1974.

Lewin, K., A dynamic Theory of Personnality. New York, McGraw-Hill, 1935.

Lewin, K., "Frontiers in Group Dynamics ». Human Relations, vol. 1, n 1, pp. 143-157, 1935.

Lewin, K., « Group Decision and Social Change ». in E. Maccoby, Readings in Social Psychology, New York, Holt, 1958.

Lussato, B., Introduction critique aux théories d'organisation. Paris, Dunod, 1997. Première édition en 1972.

MacGaffey, J., Entrepreneurs and Parasites. The struggle of indigenous capitalism in Zaïre. Cambridge, CUP, 1987. 
Maturana, H., et Varela, F., Autopoiesis and Cognition: The Realization of the Living. London, Reidl, 1980.

Maurice, M., "Méthodes comparatives et analyse sociétale: les implications théoriques des comparaisons internationales ». Sociologie du travail, ${ }^{\circ} 2,1989$.

Mayo, E., The Human Problems of an Industrial Civilisation. New York, McMillan, 1933.

Mayo, E., The Social Problems of an Industrial Civilization. Boston, Harvard University Press, 1945.

Médard, J.-F., «Le 'big man' en Afrique. Esquisse d'une analyse du politicien entrepreneur ». L'année sociologique, $\mathrm{n}^{\circ} 42,1992$, pp. 167-192.

Mercure, D., (dir.), Culture et gestion en Algérie. Paris et Montréal, L'Harmattan, 1997.

Merton, R. K., «The Unanticipated Consequences of Purposive Social Action ». American Sociological Review, 1, 1936, pp. 894-904.

Merton, R. K., «Bureaucratic Structure and Personnality ». Social Forces, XVII, 1940.

Mintzberg, H., The Nature of Managerial Work. New York, Harper and Row, 1973.

Mintzberg, H., The Structuring of Organizations. Englewood Cliffs, Prentice Hall, 1979.

Miras, C., (de), L'entrepreneur ivoirien ou une bourgeoisie privée de son état. Abidjan, Orstom, 1981.

Morgan, G., Images de l'organisation. Québec, Les Presses de l'Université Laval; Paris Editions Eska, 1989. Première édition en anglais en 1986.

Ouchi, W. G., Théorie Z: faire face au défi japonais. Paris, InterEditions, 1982. Première édition en anglais en 1981.

Pagès, M., La vie affective des groupes. Paris, Dunod, 1984.

Pascale, R. T., et Athos, A., Le management est-il un art japonais? Paris, Editions d'Organisation, 1984. Première édition en anglais en 1981.

Pauchant, T. C., «La psychologie du self, l'expérience et la vie en entreprise : une perspective kohutienne ", Chanlat, J.-F., (dir), L'individu dans l'organisation: les dimensions oubliées. Québec, Les Presses de l'Université Laval ; Paris, Editions Eska, 1990, pp. 311-335.

Peters, T. J., et Waterman, R. H., Le prix de l'excellence : les secrets des meilleures entreprises. Paris, InterEditions, 1983. Première édition en anglais en 1982.

Poncelet, M., Une utopie post-tiersmondiste: la dimension culturelle $d u$ développement. Paris, L'Harmattan, 1994.

Price, R., Society and Bureaucracy in Contemporary Ghana. Berkeley, University of California Press, 1975.

Reid, D., " Genèse du fayolisme ». Sociologie du travail, n 1, 1986, pp. 75-93.

Revue Pouvoirs, n 25, 1983.

Roitman, J., «Queries on Cultural Capitalism ». Cahiers d'Etudes Africaines, 138-139, XXXV, 2-3, 1995, pp. 629-645.

Schein, E., Organizational Culture and Leadership. San Fransisco, Jossey-Bass, 1985. 
Schwarz, A., Les dupes de la modernisation: développement urbain et sous-développement en Afrique. Montréal, Edition Nouvelle Optique, 1983.

Séguin, F., et Chanlat, J.-F., L'analyse des organisations : les théories de l'organisation (tome 1). Montréal, Editions Préfontaine inc., 1983.

Selye, H., Le stress de la vie : le probleme de l'adaptation. Paris, Gallimard, 1975. Première édition en anglais en 1956.

Selznick, P., TVA and the Grass Roots. Berkeley, University of California Press, 1949.

Serageldin, I., et Taboroff, J., (dir), Culture et développement en Afrique. Actes de la conférence internationale organisée à Washington les 2 et 3 avril 1992. Washington, BIRD/BM, 1994.

Simon, H. A., The New Science of Management Decision. New York, Harper and Row, 1960.

Simon, H. A., Le nouveau management : la décision par les ordinateurs. Paris, Economica, 1980.

Simon, H. A. et March, J. G., Organizations. New York, Wiley and Sons, 1958.

Smircich L., et Calas, M. B., « Organizational culture : a critical assessement », Jablin, F. M. Handbook of organizational communication. Beverly Hills, CA, Sage, 1987, pp. 228-268.

Spencer, H., Principles of Sociology. London, William and Norgate, 1876.

Taylor, F. W., La direction scientifique des entreprises. Paris, Dunod, 1957. Première édition en anglais en 1911.

Touraine, A., Sociologie de l'action. Paris, Seuil, 1963.

Touraine, A., Production de la société. Paris, Seuil, 1973.

Touraine, A., et coll., Lutte étudiante. Paris, Seuil, 1978.

Touraine, A., et coll., Solidarité. Paris, Fayard, 1982.

Touraine, A., et coll., Le mouvement ouvrier. Paris, Fayard, 1984.

Trist, E. L., et Bamforth, K. W., « Some Social and Psychological Consequences of the Longwall Method of Coal Getting ». Human Relations, ${ }^{\circ} 4$, pp. 3-38, 1951.

Urwick, L., « Have we Lost our Way in the Jungle of Management Theory? ». Personnel, vol. 42, $\mathrm{n}^{\circ} 3$, mai-juin, pp. 12-23, 1965.

Warnier, J.-P., L'esprit d'entreprise au Cameroun. Paris, Karthala, 1993.

Weber, M., Economie et société. Paris, Plon, 1971. Première édition en allemand en 1922.

Webber, R. A., (éd.), Culture and Management. Homeword, IL, Irwin, 1969.

Zadi Kessy, M., Culture africaine et gestion de l'entreprise moderne. Abidjan, Editions CEDA, 1998.

Zaleznick, A., et Kets de Vries, M. F. R., Power and the Corporate Mind. Boston, Houghton Mifflin, 1975.

Zaoual, H., «The Economic System of the Soussi: A Berber People of Southern Morocco ». The European Journal of Development Research, vol. 2, $\mathrm{n}^{\circ} 1$, june 1990, pp. 59-64. 
132

REVUE AFRICAINE DE SOCIOLOGIE 4(2)

Zghal, R., La culture de la dignité et le flou de l'organisation. Culture et comportement organisationnel : schéma théorique et application au cas tunisien. Tunis, Centre d'Etudes, de Recherches et de Publications, 1994.

Emmanuel Kamdem

Directeur, ESSEC

Université de Douala, Cameroun 